\title{
On-Orbit Thermal Design and Validation of 1 U Standardized CubeSat of STEP Cube Lab
}

\author{
Soo-Jin Kang and Hyun-Ung Oh \\ Space Technology Synthesis Laboratory, Department of Aerospace Engineering, Chosun University, 375 Seosuk-dong, \\ Dong-gu, Gwangju 501-759, Republic of Korea
}

Correspondence should be addressed to Hyun-Ung Oh; ohu129@chosun.ac.kr

Received 6 January 2016; Revised 20 April 2016; Accepted 22 May 2016

Academic Editor: Paolo Tortora

Copyright (C) 2016 S.-J. Kang and H.-U. Oh. This is an open access article distributed under the Creative Commons Attribution License, which permits unrestricted use, distribution, and reproduction in any medium, provided the original work is properly cited.

\begin{abstract}
The Cube Laboratory for Space Technology Experimental Projects (STEP Cube Lab) is a cube satellite (CubeSat) classified as a pico-class satellite of $1 \mathrm{U}$ (unit) size. Its main mission objective is to exploit core space technologies researched by domestic universities and verify the effectiveness of these technologies through on-orbit tests using the CubeSat. To guarantee a successful mission under extreme space thermal environments, proper thermal design is important. This paper describes the development process undertaken in the thermal design of the STEP Cube Lab, based on a passive approach, and its validation test. The system functionality and thermal design were verified through thermal vacuum and thermal balance tests under space simulated thermal vacuum environment condition. Finally, the orbital temperature of each component was predicted using a highly reliable correlated thermal mathematical model of the CubeSat obtained from the thermal balance test.
\end{abstract}

\section{Introduction}

CubeSat is a cube shaped pico-class satellite with a volume of $1000 \mathrm{~cm}^{3}$ and a mass of $1.33 \mathrm{~kg}$ or less for a standard unit of $1 \mathrm{U}$. A team of researchers at Stanford University and California Institute of Technology initiated a CubeSat program in 1999 to provide a hands-on experience for practical process of satellite development to students and engineers [1]. Due to the considerably lower development costs and shorter development times than typical commercial satellites, CubeSat provides an attractive solution for on-orbit verification of challenging space missions and technologies [2-4].

STEP Cube Lab is the first $1 \mathrm{U}$ CubeSat developed at the Space Technology Synthesis Laboratory (STSL) of Chosun University in South Korea. Its main mission objective is to exploit core space technologies researched in domestic universities and verify these technologies through on-orbit operation of the CubeSat. For a successful mission of the STEP Cube Lab, its design must be validated with consideration of all environmental conditions spanning from launch to inorbit operation. The satellite must be able to operate in harsh space thermal vacuum environment within its allowable temperature range. To guarantee the survivability and functionality of the satellite during its on-orbit mission lifetime under extreme space thermal environment conditions, proper thermal design is important for maintaining all on-board equipment within their acceptable operating temperature ranges. For passive thermal control, in general, multilayer insulation (MLI) is generally used to shield the spacecraft from incident environmental heat fluxes, while the heat dissipated by the on-board equipment is rejected into space via specific radiator surfaces coated with selective thermal coatings or second-surface mirrors. Excessive cooling through the radiator during nonoperating conditions of the equipment is compensated by a heater. In particular, passive thermal design is suitable for thermal control of CubeSats considering their restrictions in power, mass, and volume due to the extremely small accommodation space of CubeSat [5]. Yoo et al. [6] reported the thermal analysis results of a $3 \mathrm{U}$ CubeSat of TRIO-CINEMA that used a spin-stabilized attitude control method, having the advantage of thermal stabilization through continuous variation of the incidence angle between 
the satellite and incident solar flux. Ley at al. [7] reported the thermal design of a COMPASS-1 $1 \mathrm{U}$ CubeSat. This thermal design also employed a passive approach through use of black paint as a surface treatment [8]. Corpino et al. [9] developed a thermal analysis code to solve the thermal energy balance of a nanosatellite in low earth orbit (LEO) through a finite difference numerical approach. Escobar et al. [10] proposed a technique for the automatic design of a CubeSat thermal control system using a genetic algorithm that could be utilized for material layout of passive thermal control.

This paper describes the development process applied to the thermal design of the STEP Cube Lab thermal control subsystem, and its subsequent validation through a thermal vacuum test. The following sections include (1) an overview of the STEP Cube Lab mission including the mechanical configuration and features of the main mission payloads; (2) a thermal design description based on the passive approach, including thermal design drivers, requirements, thermal hardware accommodation, and thermal analysis; (3) a thermal vacuum test approach using an indirect heating plate to simulate orbital temperature conditions and the corresponding test results, including the thermal model correlation with the thermal balance test results; and (4) estimation of the thermal behavior of each component using a reliable correlated thermal mathematical model. This paper concludes that the thermal design and its validation ensure stable operation of the STEP Cube Lab system within allowable operating temperature ranges, as intended by the mission.

\section{Overview of the STEP Cube Lab}

2.1. Mission Objectives and System Descriptions. The STEP Cube Lab has been developed within the frame-work of a university program pursing educational but also scientific and technological purposes. The primary objective of its missions is to perform on-orbit verification of space-related research outputs developed at domestic universities. It was originally developed for theoretical research without verification tests for use in space. In this mission, five payloads including a variable emittance radiator (VER) [11] and a phase change material (PCM) $[12,13]$ for verifying thermal control equipment, a solar energy collection (SEC) system using a commercial Fresnel lens [14] for verifying effective power generation, a MEMS-based solid propellant thruster [15] for verifying the MEMS manufacturing process, and a nonexplosive hold-down and release mechanism (HRM) triggered by fuse wire heating [16] are verified through an onorbit test. A additional goals include on-orbit demonstration of material competence, such as that of the commercial Fresnel lens made of poly-methyl methacrylate (PMMA) and that of the MEMS thruster control board developed using commercial off-the-shelf components.

The STEP Cube Lab is operated using a circular sunsynchronous orbit with an altitude of $600 \mathrm{~km}$ and an inclination angle of $97.78^{\circ}$. The expected mission lifetime is 1 year. Taking into account the previously stated mission objective and the mechanical constraints due to the limited volume and mass of $1 \mathrm{U}$ CubeSat, a passive attitude stabilization method [17] using a permanent magnet combined with hysteresis
TABLE 1: System specification of STEP Cube Lab.

\begin{tabular}{ll}
\hline Item & Specifications \\
\hline Unit & $1 \mathrm{U}$ \\
\hline Orbit & Sun synchronous orbit \\
\hline Altitude & $600 \mathrm{~km}$ \\
\hline Inclination angle & $97.78^{\circ}$ \\
\hline Period & $5801.23 \mathrm{sec}$ \\
\hline Life time & 1 year \\
\hline & Variable emittance radiator (VER) \\
& Phase change material (PCM) \\
Payloads & Solar energy collection system (SEC) \\
& MEMS-based solid propellant thruster \\
& Hold-down and release mechanism (HRM) \\
\hline Mass & 0.92 kg \\
\hline Thermal control & Passive \\
\hline Attitude control & Permanent magnet attitude stabilization \\
\hline Communication & UHF (437.485 MHz) \\
\hline
\end{tabular}

dampers was selected due to its simplicity, small mass, and volume of attitude control system. The permanent magnet is used to generate control torques aligning the body axis of the satellite with the Earth's magnetic field lines. Hysteresis dampers are used to dampen oscillations of the satellite, induced immediately after being released from the launcher. As a result, the satellite performs two rotations per orbit. This provides the advantage of thermal stabilization of the satellite, because the incidence angle between the satellite and the solar flux vector is continuously changing. Table 1 lists the basic specifications of the STEP Cube Lab.

2.2. Satellite's Configuration and Mission Payloads. Figure 1 shows the mechanical configuration of the STEP Cube Lab; its design was based on a $1 \mathrm{U}$ standardized CubeSat. The total mass of the satellite is $0.92 \mathrm{~kg}$, with a margin of $0.41 \mathrm{~kg}$ with respect to the requirement of $1.33 \mathrm{~kg}$ for $1 \mathrm{U}$ CubeSats. The total generated power is $2.2 \mathrm{~W}$, with a margin of $0.5 \mathrm{~W}$ with respect to the required power of $1.7 \mathrm{~W}$. All structural elements were manufactured by aluminium alloy (Al-6061) with a black anodizing treatment. Four of six external panels were covered with gallium arsenide triple junction solar cells on the $+X,-X,+Y$, and $-Y$ panels. To maximize the accommodation efficiency, a commercial UHF half-duplex antenna [18] combined with buck converter for UHF communication mode transition $(437.485 \mathrm{MHz})$ was considered. To secure the structural safety of the deployable antenna under launch conditions, the antenna was fixed by a nylon wire on the upper $+Z$ panel of the interface board, having the function of electrical interface management, and was released by a fuse wire heating trigger. A Global Positioning System (GPS) antenna was also installed on the $+Z$ panel for the satellite time synchronization and position data acquisition after MEMS thruster activation. Electronic boards of Onboard Computer (OBC), Electrical Power System (EPS) with a Li-ion battery, communication, GPS, and payload plate stacked together were fixed to the upper and lower 


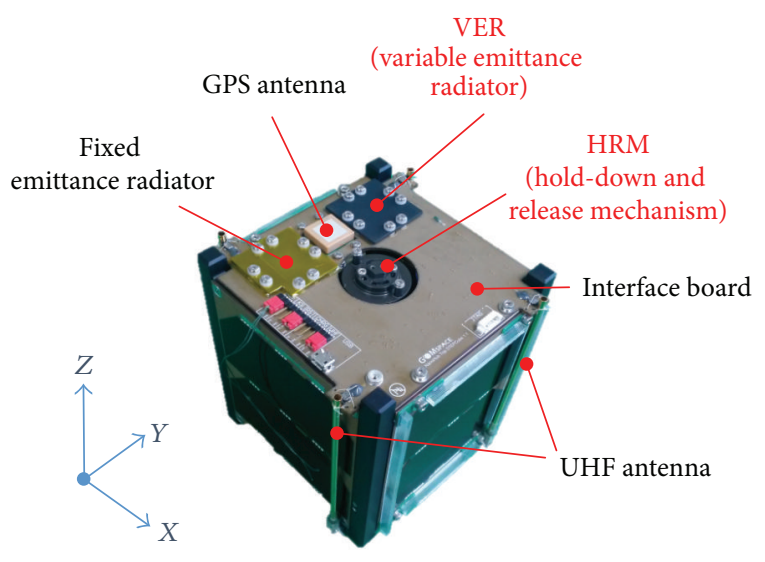

(a)

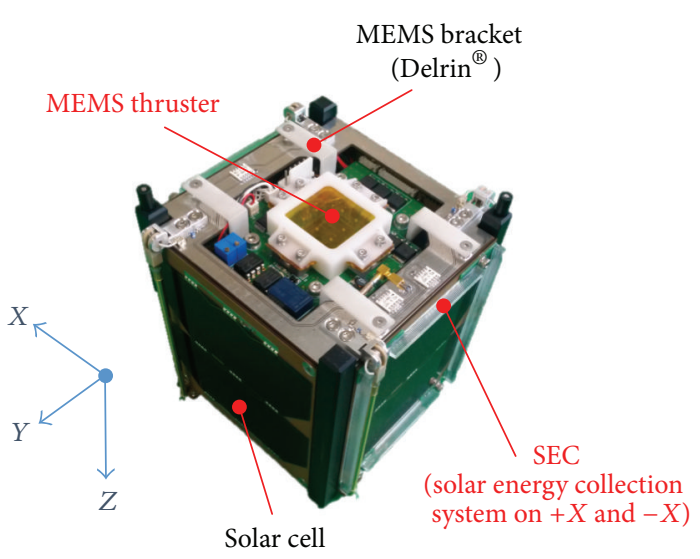

(b)

HRM

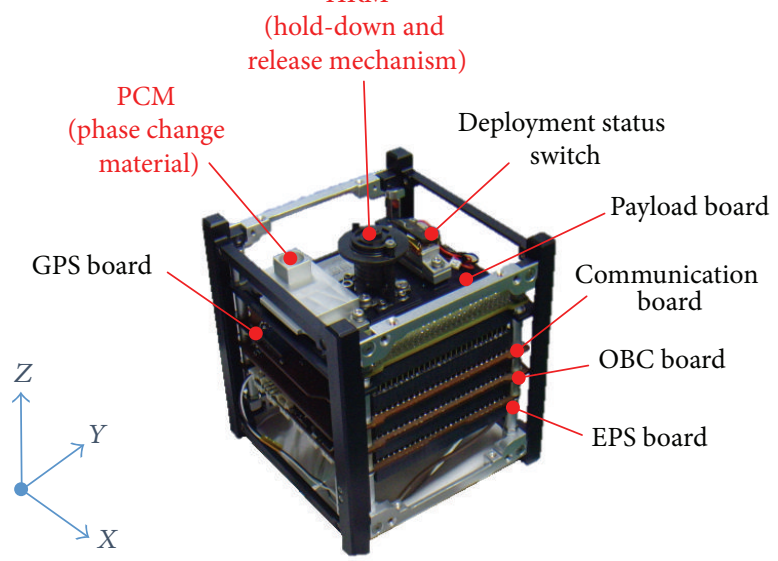

(c)

FIGURE 1: Mechanical configuration of the STEP Cube Lab ((a) and (b) external configuration, (c) internal configuration).

CubeSat structures by using Printed Circuit Board (PCB) supporters. The payload plate was manufactured using Al6061 for mounting the mission payloads of the PCM and the HRM assembly with a deploy status switch.

Figures 2, 3, 4, 5, and 6 show the developed on-board payloads to be verified in this mission. The location of each payload is also shown in Figure 1. The VER and the PCM selected for the purpose of on-orbit verification of thermal control device are shown in Figures 2 and 3. The VER shown in Figure 2(a) was installed on the $+Z$ panel and is a smart radiation device based on the metal insulator transition of a (La,Sr) $\mathrm{MnO}_{3}$ thin film, which significantly varies in its emittance value according to the temperature variation as shown in Figure 2(b). It may be effective in minimizing additional heater power consumption under cold conditions, unlike conventional radiators with fixed emittance values. The effectiveness of the VER will be verified by comparing the on-orbit temperature profile with that of the fixed emittance radiator (FER) coated with Kapton tape installed near the VER shown in Figure 1.

The PCM shown in Figure 3(a) was positioned on the payload plate inside of the satellite and its location is shown in Figure 1(c). Figure 3(b) shows the verification test results of PCM. The PCM is a heat storage device that can store and release latent heat energy through a solid-liquid phase change at the designated temperature. Therefore, it is capable of achieving efficient heat management with a less mass than the conventional heat sink mass. A paraffin $\mathrm{n}$-pentadecane of $2 \mathrm{~g}$ with a phase change temperature of $10^{\circ} \mathrm{C}$ was selected as functional fluid for the PCM, considering the temperature range of the satellite predicted using on-orbit thermal analysis. Total latent heat of the PCM developed in this study is $326 \mathrm{~J}$.

The HRM shown in Figure 4 was positioned in the middle of the payload plate. Figure 4(a) shows images captured by the high-speed camera in a successful release of the mechanism at the lower limit of the qualification temperature $\left(-20^{\circ} \mathrm{C}\right)$ obtained during the qualification test at the mechanism level [16]. Figure 4(b) shows the deployed and stowed configurations of the mechanism module on the payload plate, composed of the HRM and deployment status switch used to evaluate successful on-orbit operation. The activation principle of the mechanism was based on the cutting of a nylon cable triggered by fuse wire heating generally used in cube satellite applications. A high axial load capability 


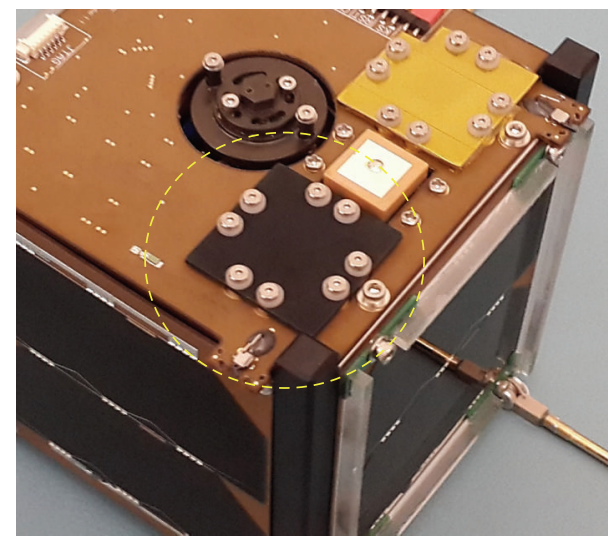

(a)

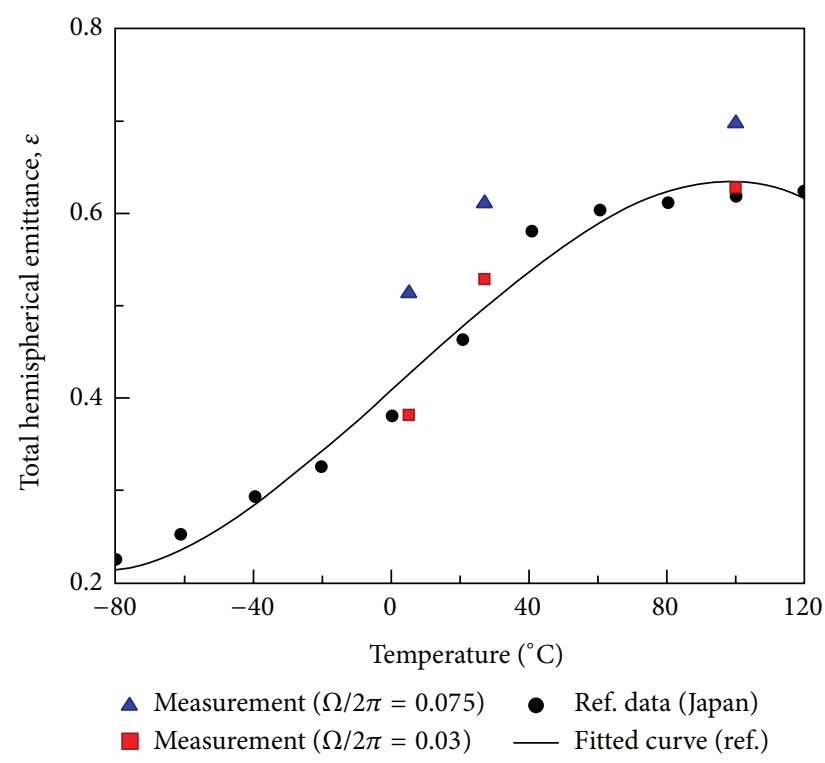

(b)

FIGURE 2: Variable emissivity radiator (VEM).

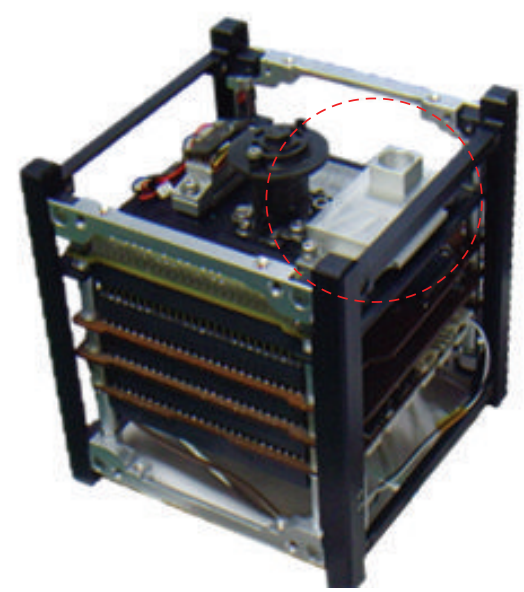

(a)

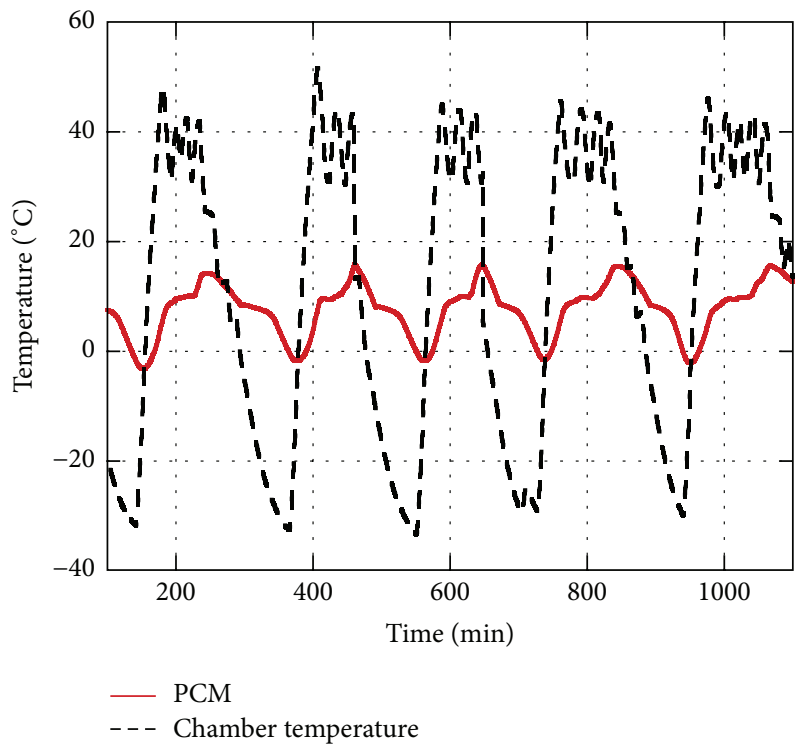

(b)

FIGURE 3: Phase change material (PCM).

of the mechanism was achieved by clamping the constraint bolt to the separation nut, which is constrained by the nylon cable winding. This offered several advantages, such as a large holding capacity and negligible induced shock compared to conventional fuse wire release mechanisms used in CubeSat applications. Successful release of the mechanism on-orbit is evaluated by a deployment status switch.

To enhance the power generation performance of CubeSats given their mass and volume limitations, an SEC system using a Fresnel lens was employed and its performance was verified by on-orbit testing. Figure 5(a) illustrates the basic operating principle of the SEC system. The system enhances power generation performance by concentrating and illuminating solar energy onto the solar panels using a commercial Fresnel lens installed at the edge of a solar panel as shown in Figure 1(b) even in the worst case scenario of the sun's incidence angle $(\beta=0)$. Figure $5(b)$ shows the test results of the SEC system using a Fresnel lens and solar simulator indicating that the SEC system using a Fresnel lens generates energy much more efficiently than without the lens system [14]. The Fresnel lens was installed at the edge of the solar panels in the $+X$ and $-X$ directions, as shown in Figure 1(b), to verify the proposed solar energy collection system by comparing the power generation performance between the solar panels with and without the Fresnel lens.

A MEMS-based solid propellant thruster array in Figure 6 was installed in the $-Z$ direction of the satellite. The objective of on-orbit verification of the MEMS thruster is to verify the MEMS fabrication process for use in space rather than its attitude determination capabilities. Long-term reliability of this technology must be established through experiments in space in order to achieve the goal of sending a completely microfabricated and integrated MEMS system into space. MEMS technology is very attractive for space applications because of largely reduced size, mass, and power 

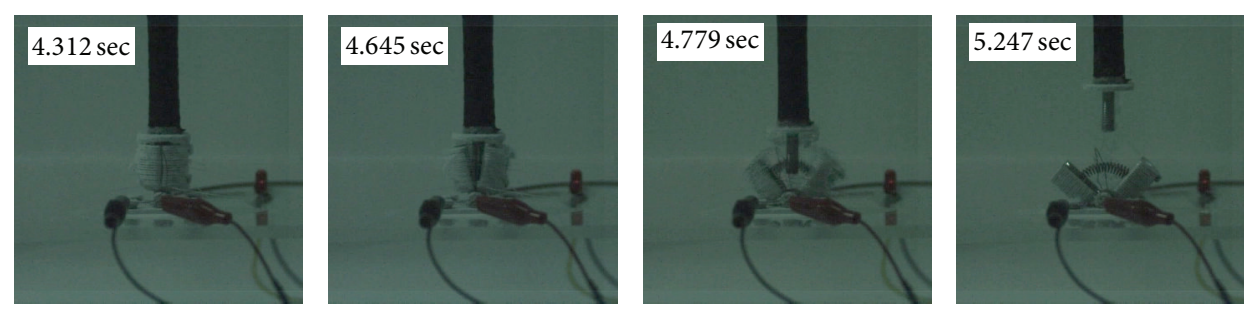

(a)
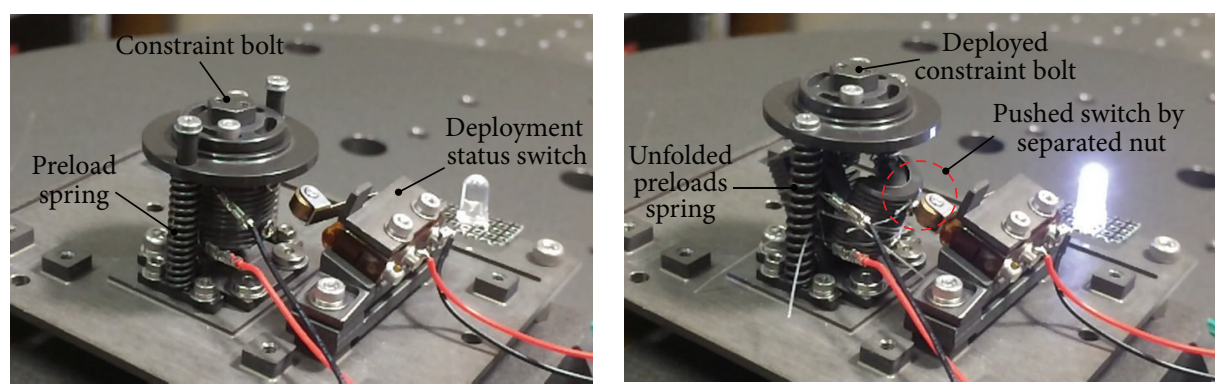

(b)

FIgURE 4: Nonexplosive hold-down and release mechanism (HRM).

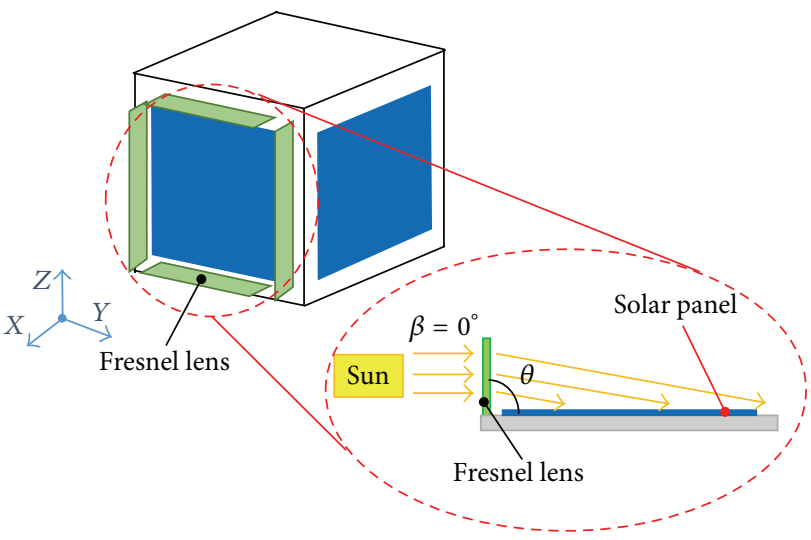

(a)

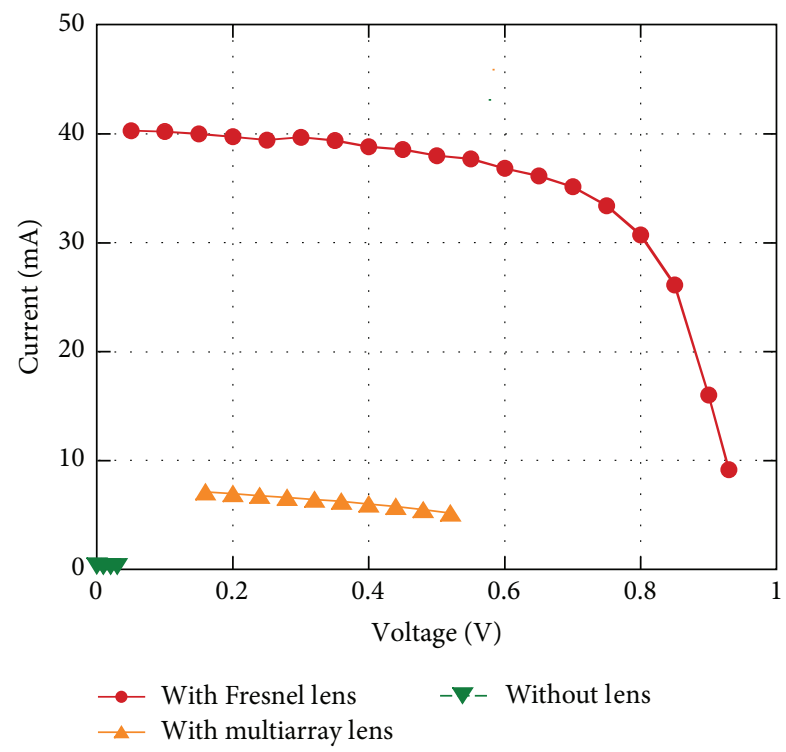

(b)

FIGURE 5: Solar energy collection system using Fresnel lens (SEC).

consumption through miniaturization of its components and systems. Figure 6(a) shows the cross section of the MEMS solid thruster developed by Lee et al. [15]. The operation principle is as follows: when the solid propellant reaches ignition temperature achieved by the microigniter, the glass membrane is subsequently broken by the high-energy combustion gases of the solid propellant. Thrust is then generated through the micronozzle. The microigniter is also used as a microresistance temperature detector to judge the status of thruster. Figure 6(b) shows an exploded schematic view of the MEMS thruster module composed of the MEMS thruster and control board. To achieve reliable electrical contact and survivability, electrode pads design was used in conjunction with spring-loaded pogo-pins. As shown in the exploded schematic view of Figure 6(b), the electrical interface on the thruster was directly connected to the pogo-pins on the thruster control board and fixed by a plastic cover made of Delrin with space heritage. To ensure successful on-orbit verification of the MEMS thruster array, structural design efforts at the satellite level were performed to minimize the launch loads transmitted to the thruster under launch environments. This was achieved by mounting the MEMS 

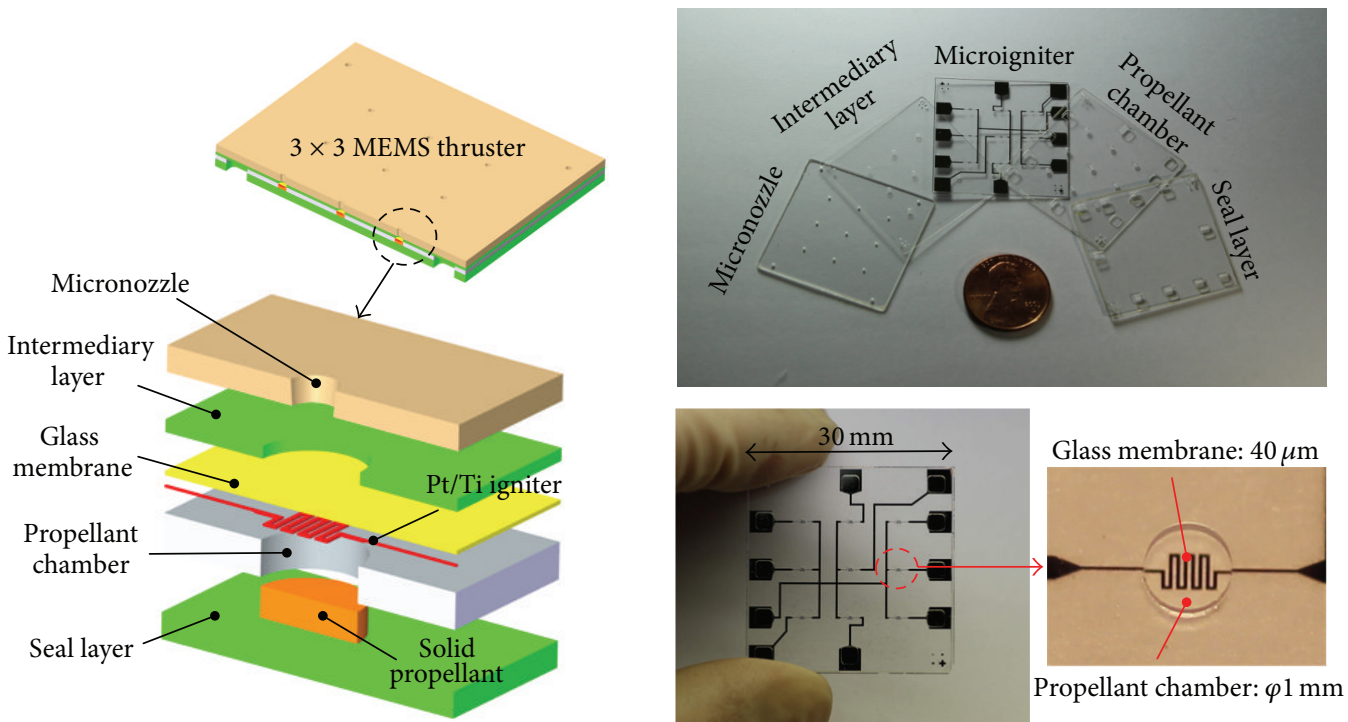

(a)

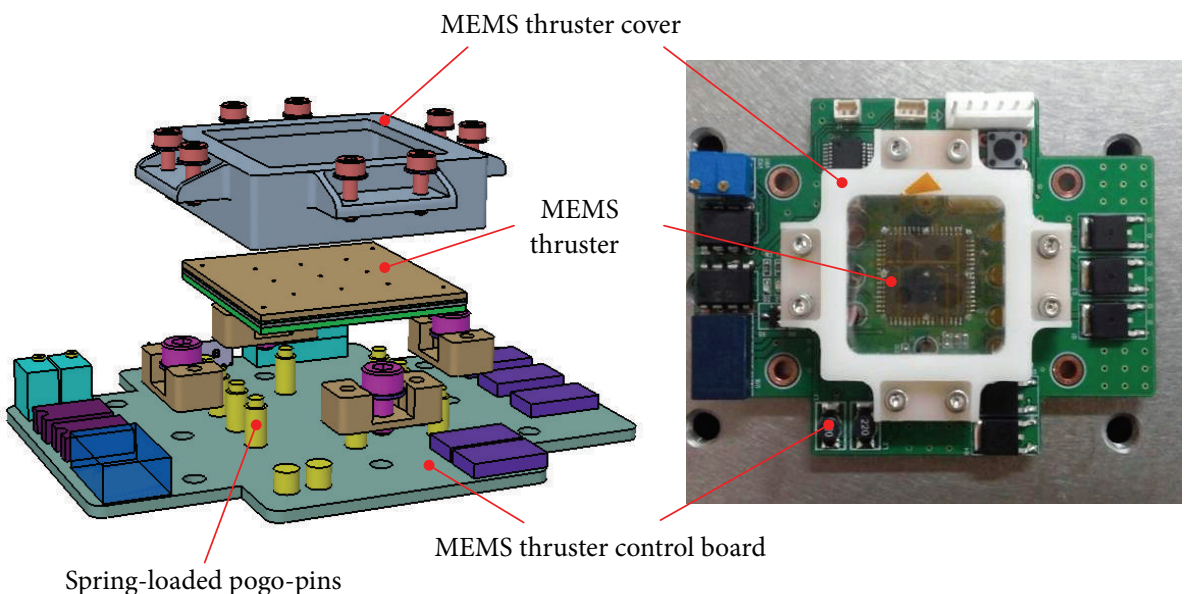

(b)

FIGURE 6: MEMS-based solid propellant thruster.

thruster module on flexure-like brackets made of Delrin plastic material, as shown in Figure 1(b). This design also facilitated external access to and replacement of the MEMS thruster without demating other parts of the CubeSat. This was valuable since frequent replacements of the thruster were required during the verification test.

Table 2 summarizes the main features and specifications of the payloads developed for the STEP Cube Lab mission.

\section{Thermal Design and Analysis}

3.1. Description of Thermal Design. The main objective of thermal design is to maintain on-board equipment within the required temperature limits for ensuring a successful on-orbit mission. For example, the MEMS solid thruster was developed purely for academic research as its function and performance have been verified in laboratory level experiments. In addition, attachment of an additional heater and sensor on the thruster was not possible due to dimensional constraints. Therefore, it is important to establish moderate temperature conditions through thermal design at the satellite system level to guarantee successful on-orbit operation.

The thermal design techniques are based on either passive or active approach, but the former is widely preferred for university CubeSats [6-10]. In this study, a passive approach was used as the basis of the thermal design, considering design restrictions of a $1 \mathrm{U}$ CubeSat. Passive thermal design maintains the on-board equipment within their allowable operating temperature limits shown in Table 3 by using suitable material selection, surface finishes with adequate thermooptical properties, and thermal insulation based on passive thermal design.

Figure 7 shows the thermal hardware configuration of the thermal control subsystem of the STEP Cube Lab. The interface board and MEMS thruster in the $+Z$ and $-Z$ directions are covered by MLI to reduce excessive thermal flux from/to 


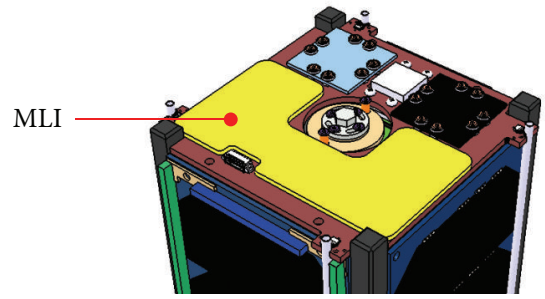

(a)

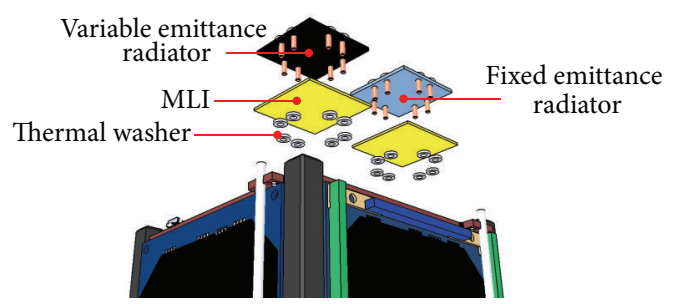

(c)

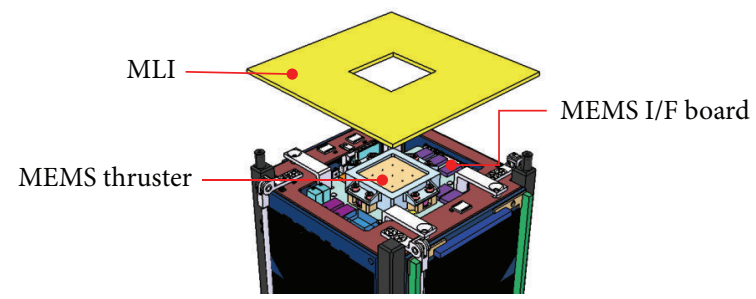

(b)

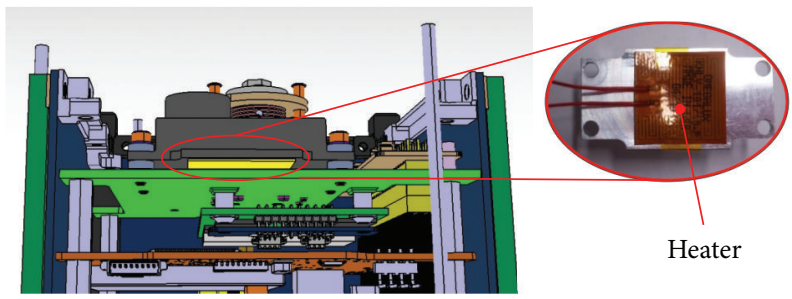

(d)

FIGURE 7: Accommodation of thermal control hardware.

TABLE 2: Specification of mission payloads for STEP Cube Lab.

\begin{tabular}{ll}
\hline Payload & Specification \\
\hline VER & Dimension: $30 \mathrm{~mm} \times 30 \mathrm{~mm}$ \\
& Emissivity: $0.28\left(\right.$ at $\left.-40^{\circ} \mathrm{C}\right), 0.41$ (at $\left.0^{\circ} \mathrm{C}\right)$, \\
& and $0.54\left(\right.$ at $\left.+40^{\circ} \mathrm{C}\right)$
\end{tabular}

components as shown in Figures 7(a) and 7(b). MLI used in this program consists of 12 inner layers of $1 / 4$ mil aluminized Myler, innermost and outermost layers of 1 mil aluminized Kapton with effective emissivity of 0.8 and solar absorptivity of 0.4. To minimize the external effects on the performance of variable and fixed emittance radiators for proper verification on-orbit, the radiators are radiatively and conductively insulated from the satellite using a thermal washer with $2 \mathrm{~mm}$ thickness of G10 and MLI, as shown in Figure 7(c). A thin film heater was attached to the bottom of the PCM as shown in Figure $7(\mathrm{~d})$, if an additional heat source is necessary to create temperature condition for monitoring a phase change transition region on-orbit. In the thermal design of STEP Cube $\mathrm{Lab}$, there is not any heat transport path from the stacked
TABLE 3: Allowable operating temperature for STEP Cube Lab components.

\begin{tabular}{lccc}
\hline Unit & $\begin{array}{c}\text { Heat } \\
\text { dissipation } \\
{[\mathrm{W}]}\end{array}$ & \multicolumn{2}{c}{$\begin{array}{c}\text { Allowable temperature } \\
\text { range }\left[{ }^{\circ} \mathrm{C}\right]\end{array}$} \\
\hline EPS board & 0.10 & -40 & +85 \\
Battery & 0.60 & -20 & +60 \\
Interface board & 0.03 & -40 & +85 \\
Communication board & 0.27 & -30 & +60 \\
OBC board & 0.11 & -40 & +85 \\
GPS board & 0.27 & -40 & +85 \\
MEMS control board & 0.01 & -35 & +60 \\
Solar panels & - & -100 & +100 \\
SEC & - & -70 & +80 \\
HRM & - & -35 & +50 \\
MEMS thruster & - & -35 & +60 \\
\hline
\end{tabular}

electronic boards to the dedicated radiator because the generated heats are mainly dissipated by radiation.

3.2. Thermal Analysis. The objective of the thermal analysis is to confirm that the thermal design meets the temperature requirements shown in Table 3 for all equipment during the mission phase. Heat dissipation values used for the analysis are also summarized in Table 3. Table 4 lists the orbital conditions used in the on-orbit thermal analysis for the STEP Cube Lab. In the thermal analysis, we defined the worst hot and cold cases in order to consider the critical temperature conditions of the satellite described in Table 4 . The worst hot condition corresponds to the case in which the satellite with maximum heat dissipation of the components is operated during the winter solstice with the highest incoming heat flux. In contrast, the worst cold condition corresponds to the case 
TABLE 4: Orbital thermal condition for the worst case thermal analysis.

\begin{tabular}{lcc}
\hline \multirow{2}{*}{ Parameter } & \multicolumn{2}{c}{ Orbital thermal condition } \\
& Worst cold & Worst hot \\
\hline Solar flux $\left[\mathrm{W} / \mathrm{m}^{2}\right]$ & 1287 & 1420 \\
Albedo & 0.30 & 0.35 \\
IR flux $\left[\mathrm{W} / \mathrm{m}^{2}\right]$ & 227 & 249 \\
Season & Summer & Winter \\
\hline
\end{tabular}

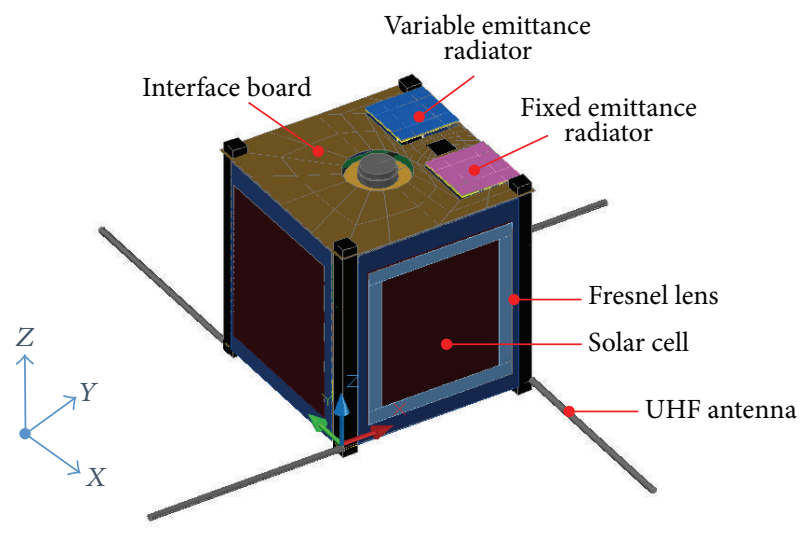

(a)

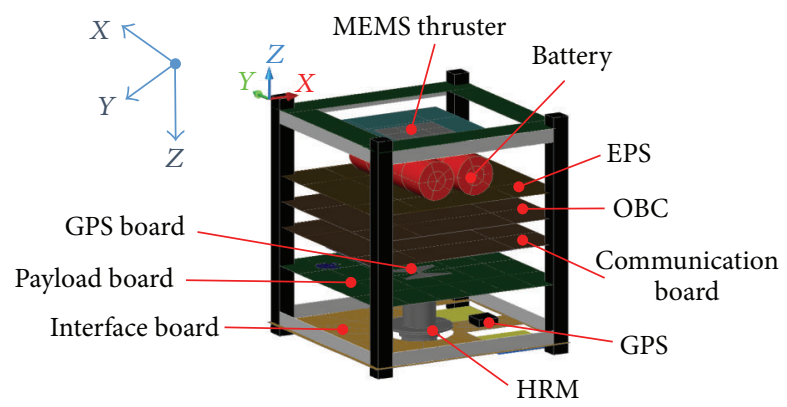

(b)

FIgURE 8: TMM of STEP Cube Lab ((a) external, (b) internal).

in which the satellite is operated at the emergency condition when the EPS, OBC, and communication boards are operated during the summer solstice with the lowest incoming heat flux.

Figures 8(a) and 8(b) show the internal and external configuration of thermal mathematical model (TMM) of the STEP Cube Lab for the on-orbit thermal analysis and 420 nodes were used for thermal modeling. This was constructed in Thermal Desktop, a CAD-based geometric interface of the commercial on-orbit thermal analysis tool of Systems Improved Numerical Differencing Analyzer/Fluid Integrator (SINDA/FLUINT) $[19,20]$. The GMM and the output of RadCAD, which is a module to calculate radiation exchange factors and orbital heating rates, are analyzed by SINDA/FLUINT as the input. The general heat-balance equation for element $i$ coupled with elements $j$ through $n$ is given as

$$
C_{i} \frac{d T_{i}}{d t}=Q_{i}-\sum_{j=1}^{n} C_{i j}\left(T_{i}-T_{j}\right)-\sum_{j=1}^{n} R_{i j} \sigma\left(T_{i}^{4}-T_{j}^{4}\right),
$$

where $C_{i}$ is the heat capacity of node $i ; T_{i}$ and $T_{j}$ are the temperatures of nodes $i$ and $j$, respectively; $Q_{i}$ is the power input of node $i ; C_{i j}$ is the linear conductance from element $i$ to element $j$; and $R_{i j}$ is the radiation coefficient of nodes $i$ and $j$. For on-orbit thermal analysis using SINDA/FLUINT, the heat-balance equation described in (1) is calculated using the average of the temperature derivatives at the current and following time steps to predict the overall temperature change, as shown in the following equation:

$$
\begin{aligned}
& \frac{2 C_{i}}{\Delta t}\left(T_{i}^{n+1}-T_{1}^{n}\right)=2 Q_{i}+\sum_{j=1}^{N}\left[G_{i j}\left(T_{i}^{n}-T_{j}^{n}\right)\right. \\
& \left.+\widehat{G}_{i j}\left(\left(T_{1}^{n}\right)^{4}-\left(T_{j}^{n}\right)^{4}\right)\right]-\sum_{j=1}^{N}\left[G_{i j}\left(T_{i}^{n+1}-T_{j}^{n+1}\right)\right. \\
& \left.\quad+\widehat{G}_{i j}\left(\left(T_{i}^{n+1}\right)^{4}-\left(T_{j}^{n+1}\right)^{4}\right)\right]
\end{aligned}
$$

where $T_{j}^{n}$ is the temperature of node $j$ at the current time step $t, T_{i}^{n+1}$ is the temperature of node $i$ at the next time step $t+\Delta t$, $G_{j i}$ is a linear conductor that attaches node $j$ to node $i, \widehat{G}_{j i}$ is a radiation conductor that attaches node $j$ to node $i$, and $C_{i}$ is the thermal capacitance of node $i$.

In the analysis, the orbital profiles of the STEP Cube Lab with the permanent magnet stabilization strategy under orbital conditions defined in Table 4 are shown in Figure 9. This strategy has the advantage of obtaining better thermal stabilization of the satellite with the solar incidence angle continuously varying along the orbit. Tables 5 and 6 summarize the material and thermooptical properties used in the thermal analysis. Solar absorptance value of 0.24 for VER with $(\mathrm{La}, \mathrm{Sr}) \mathrm{MnO}_{3}$ perovskite-type structure can be achieved by applying multilayer film coating evaporated on the surface of the radiator by the electron beam evaporation method [21].

The calculated contact conductance values that are used in the thermal networks to evaluate the node to node or surface to surface links are summarized in Table 7.

Figure 10 shows the temperature profiles of the representative node of each external panel, except for the $-Z$ panel with the MEMS thruster, for the worst hot case, Figure 10(a), and cold case, Figure 10(b), along four orbits after stabilization from the initial condition. The figure shows that the minimum and maximum temperature range from $-40^{\circ} \mathrm{C}$ to $60^{\circ} \mathrm{C}$ with enough margin with respect to the operating temperature requirements described in Table 3 . In addition, the interface board newly developed in this program operated under more moderate temperature conditions than the others. The maximum cold and hot temperature were $-30^{\circ} \mathrm{C}$ to $20^{\circ} \mathrm{C}$, respectively. Figure 11 shows the temperature profiles of the payloads for the worst hot case, Figure 11(a), and cold case, Figure 11(b). The results obtained from the VER are also 


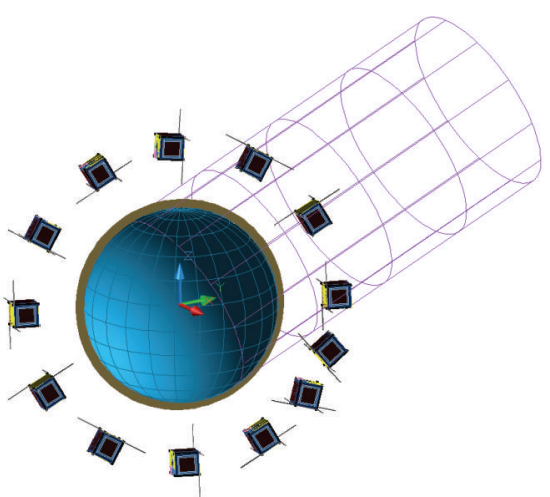

(a)

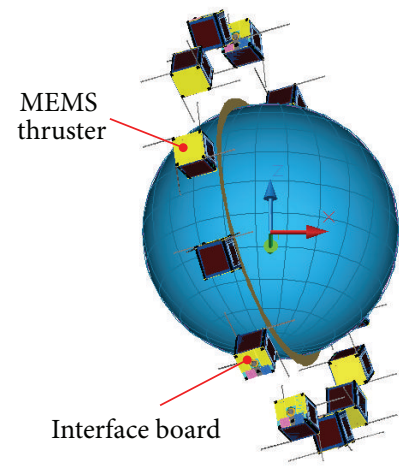

(b)

FIGURE 9: Orbit profile of STEP Cube Lab with permanent magnet stabilization strategy ((a) view from the orbit normal direction, (b) view from the sun).

TABLE 5: Summary of material properties used in the analysis.

\begin{tabular}{|c|c|c|c|c|}
\hline Component & Material & Density $\left[\mathrm{kg} / \mathrm{m}^{3}\right]$ & $\begin{array}{c}\text { Thermal conductivity } \\
{[\mathrm{W} / \mathrm{m}-\mathrm{K}]}\end{array}$ & Specific heat $[\mathrm{J} / \mathrm{kg} / \mathrm{K}]$ \\
\hline Structure & Al6061-T6 & 2700 & 171 & 920 \\
\hline $\mathrm{PCB}$ & FR4 & 1900 & 0.1 & 1200 \\
\hline Solar cell & ITO-GaAs & 5316 & 46.05 & 350 \\
\hline Battery & Lithium-ion & 3.045 & 0.09 & 879.2 \\
\hline Delrin & $\begin{array}{c}\text { Acetal } \\
\text { homopolymer }\end{array}$ & 1410 & 0.4 & - \\
\hline MEMS thruster & Quartz glass & 2210 & 1.5 & 0.198 \\
\hline SEC & PMMA & 1190 & 0.21 & 1470 \\
\hline Radiator & Stainless steel & 8030 & 16.2 & 500 \\
\hline MLI & $\begin{array}{l}\text { Aluminized } \\
\text { Kapton/Myler }\end{array}$ & 350 & $\begin{array}{c}4.2 \text { at }-100^{\circ} \mathrm{C} \\
6.3 \text { at }-50^{\circ} \mathrm{C} \\
9.2 \text { at } 0^{\circ} \mathrm{C} \\
13.2 \text { at } 50^{\circ} \mathrm{C} \\
16.0 \text { at } 75^{\circ} \mathrm{C} \\
18.8 \text { at } 100^{\circ} \mathrm{C}\end{array}$ & - \\
\hline
\end{tabular}

TABLE 6: Summary of thermooptical properties used in the analysis.

\begin{tabular}{lcccc}
\hline Component & Optical property & $\alpha$ & $\varepsilon$ & $\alpha / \varepsilon$ \\
\hline Structure & Black anodize & 0.88 & 0.88 & 0.85 \\
\hline Solar cell & ITO-GaAs & 0.92 & 0.10 & 1.0 \\
\hline MEMS thruster & Quartz glass & 0.90 & 0.04 & 0.1 \\
\hline SEC & PMMA & 0.04 & 0.37 & 1.0 \\
\hline FER & Kapton tape & 0.2 & 0.28 at $-40^{\circ} \mathrm{C}$ \\
\hline VER & (La,Sr)MnO & 0.41 at $0^{\circ} \mathrm{C}$ & 0.54 \\
\hline MLI & & 0.24 & 0.54 at $+40^{\circ} \mathrm{C}$ \\
\hline
\end{tabular}

plotted in the figure and compared with those from the EFR. The results show that all payloads were within the temperature range of operating conditions. In the case of the PCM, we confirmed that the temperature variation was sufficient to monitor a transition of phase change temperature of $10^{\circ} \mathrm{C}$.
The temperature values from the VER whose emissivity varied according to the environment temperature showed lower and higher values than the fixed emissivity radiator under hot and cold conditions, respectively. Figure 12 shows the temperature profiles of the electronic boards for the worst hot 
TABLE 7: Summary of conductor values used in the analysis.

\begin{tabular}{lccc}
\hline Coupling condition & Type of contact & Contact values & Remarks \\
\hline Structure/external panel & & 417.6 & Bolting \\
Structure/interface board & Surface to Surface $\left[\mathrm{W} / \mathrm{m}^{2}-^{\circ} \mathrm{C}\right]$ & 30.00 & Bolting \\
External panel/solar cell & & 30.00 & - \\
\hline MEMS thruster/structure & & 0.001 & Delrin \\
RER,VER/interface board & Node to Node $\left[\mathrm{W} /{ }^{\circ} \mathrm{C}\right]$ & 0.001 & G10 washer \\
PCM/payload board & & 0.001 & G10 washer \\
Electrical board/board & & 0.001 & PCB supporter \\
Battery/power board & & 0.407 & Partial clamping \\
SEC/solar cell & & 0.001 & Bonding \\
\hline
\end{tabular}

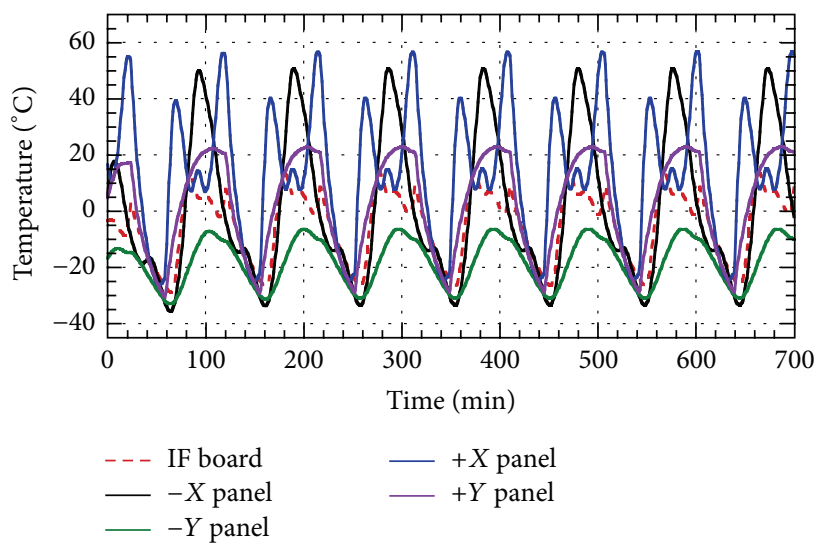

(a)

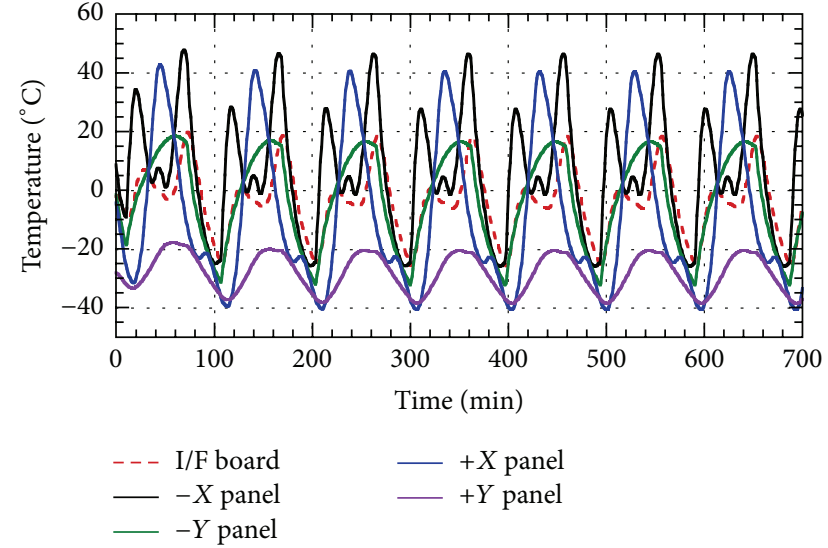

(b)

FIGURE 10: Temperature profiles of external panels ((a) worst hot case, (b) worst cold case).

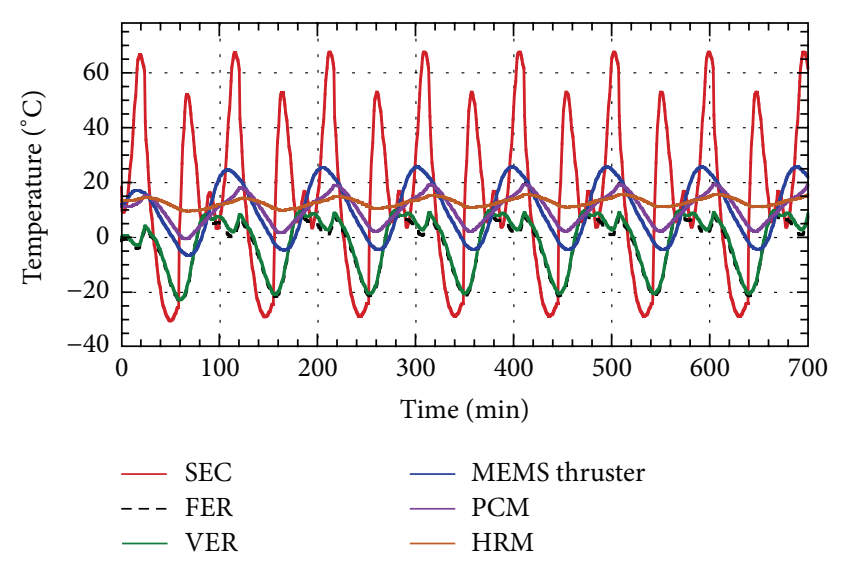

(a)

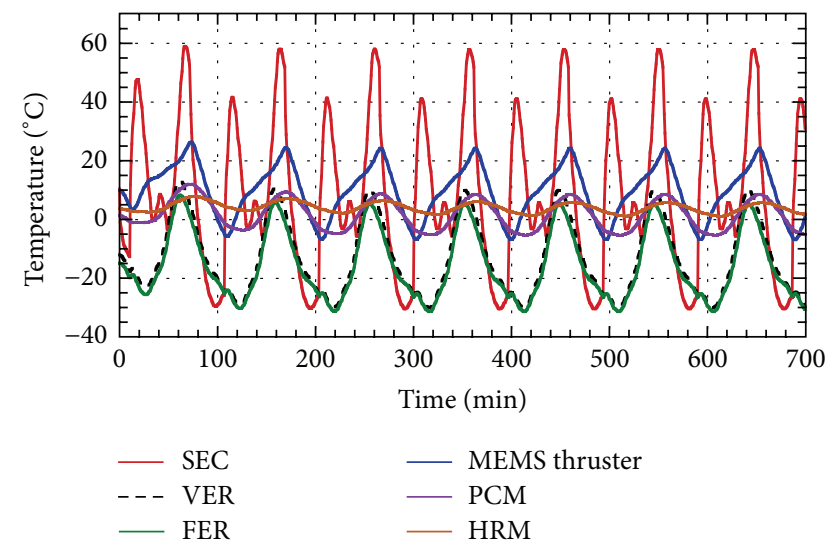

(b)

FIGURE 11: Temperature profiles of payloads ((a) worst hot case, (b) worst cold case).

case, Figure 12(a), and cold case, Figure 12(b), which result within the required temperature limits with adequate margin, although the battery experienced the lowest temperature peak of $-5^{\circ} \mathrm{C}$ at the worst cold case of emergency mode.

\section{Thermal Vacuum Test and Validation}

4.1. Description of the Thermal Vacuum Test. The objective of the thermal vacuum (TV) test was to verify the functional performance and effectiveness of the thermal design of the satellite in a space simulated thermal vacuum environment. Figure 13 shows the TV test set-up configuration of the STEP Cube Lab inside of the $\phi 1 \mathrm{~m}$ TV chamber. The satellite is installed on the mechanical supports made of Delrin plastic material for conductive thermal isolation because such a small CubeSat with a small heat budget, the heat leakage through the supports is an important contribution for the thermal balance. In the test, a total of 25 thermocouples were 


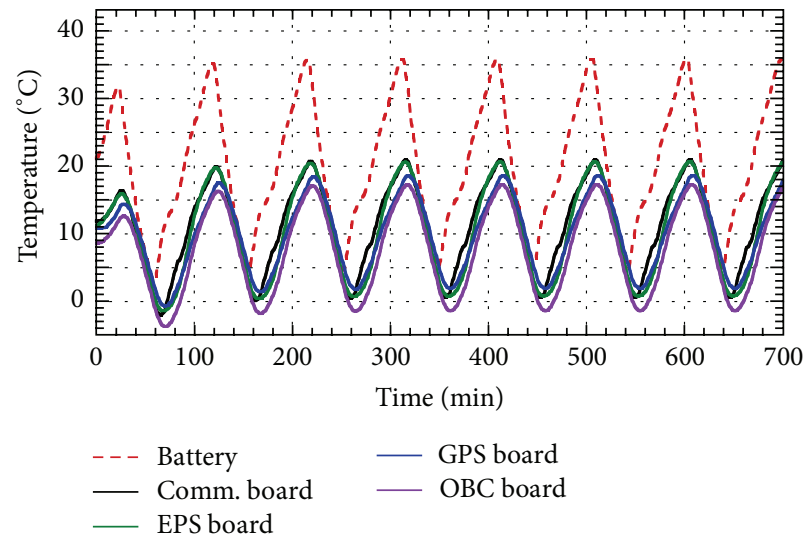

(a)

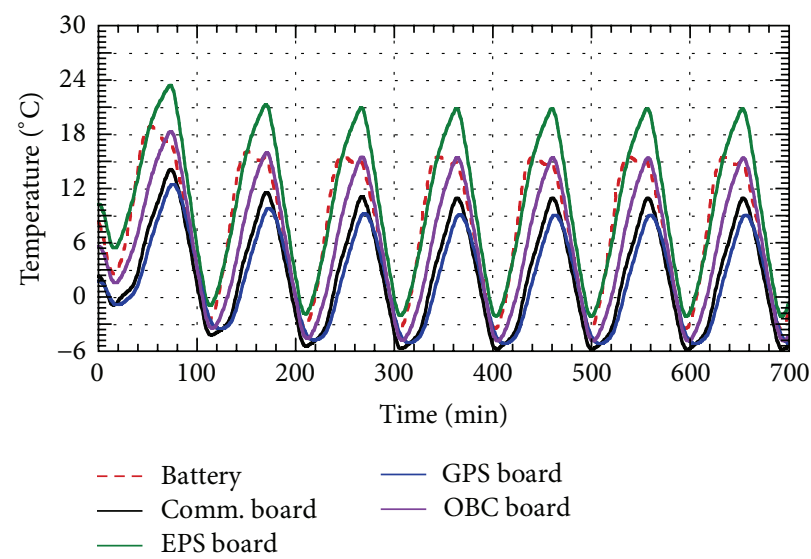

(b)

FIgURE 12: Temperature profiles of electronic boards ((a) worst hot case, (b) worst cold case).
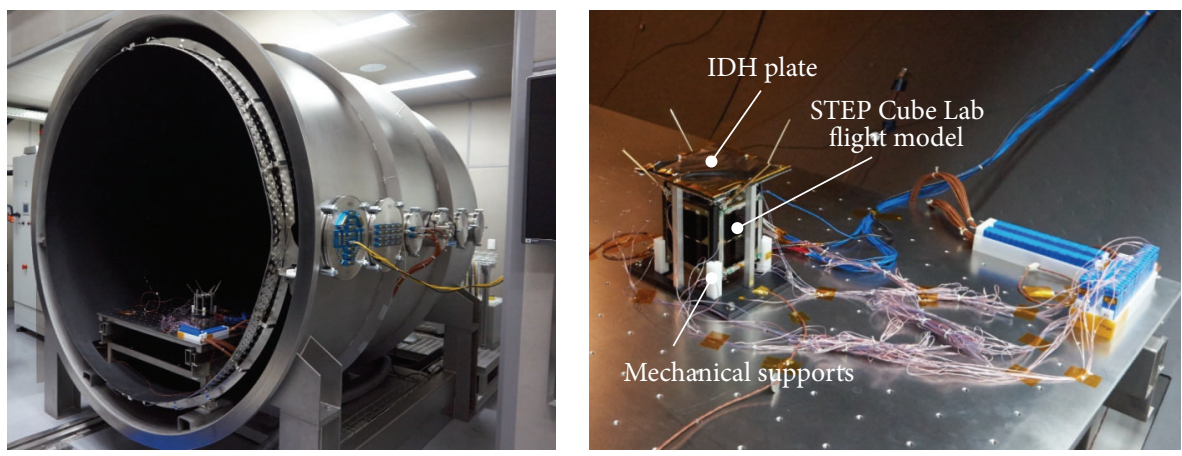

FIgURE 13: Thermal vacuum test set-up.

attached to the main components. The temperature reference point (TRP) was on the interface board to assess the stabilized target temperature. The test was performed at an acceptance level of $-35^{\circ} \mathrm{C} / 35^{\circ} \mathrm{C}$ based on the TRP. This was derived from the thermal analysis considering the uncertainty margin of $5^{\circ} \mathrm{C}$. In this test condition, the estimated maximum temperatures of the solar panels on the $+X,-X,+Y$, and $-Y$ panels were approximately $20^{\circ} \mathrm{C}$ higher and lower than the maximum hot and cold temperatures. However, this was not determined to be a critical problem because the panels were previously qualified through other CubeSat missions. That was the reason why the TRP was set on the newly developed interface board, because this was important from a verification point of view. The target temperature was achieved by raising and lowering the shroud temperature of the chamber. In the test, the satellite was exposed to two thermal cycles, including a thermal balance (TB) test conducted at a pressure less than $10^{-5}$ torr. The baseline for the dwell time at hot and cold plateaus of the system function test was more than two hours and the required temperature change rate to declare the equilibrium condition for the thermal balancing test was less than $1^{\circ} \mathrm{C}$ variation per hour.

Figure 14 shows the TV test profiles applied to the system functional verification of the STEP Cube Lab. During the TV test, full system functional tests were conducted at both hot and cold soak phases to check the state of health and verify normal functionality in the space simulated thermal vacuum environment. In the last cold soak phase of G in Figure 14, a separation test of the HRM was conducted because this is the worst condition for HRM activation. The microresistance temperature detector (RTD) of the MEMS thruster was calibrated with the temperature data directly acquired by the thermocouples from TV chamber data acquisition system during three temperature stabilization periods. The accuracy of the sensor is not important because the data is used for only monitoring the status of the thruster on-orbit. Hot and cold thermal balance tests at soak phases of G and I of Figure 14 were conducted to obtain the balanced temperature data used for obtaining highly reliable TMM of the satellite by correlating the model with the test data.

The feature of the TV test performed in this study is to apply an indirect heating (IDH) plate as shown in Figure 15, to more effectively simulate the different temperature conditions of each panel on-orbit. For example, if the TRP temperature reached the target cold temperature threshold, there was a possibility that the temperature of the MEMS thruster and battery near the thruster was excessively cooler than the predicted on-orbit temperature; the IDH installed near the MEMS thruster as shown in Figure 15 provided local heat flux to the $-Z$ side of the CubeSat. Figure 15 shows 


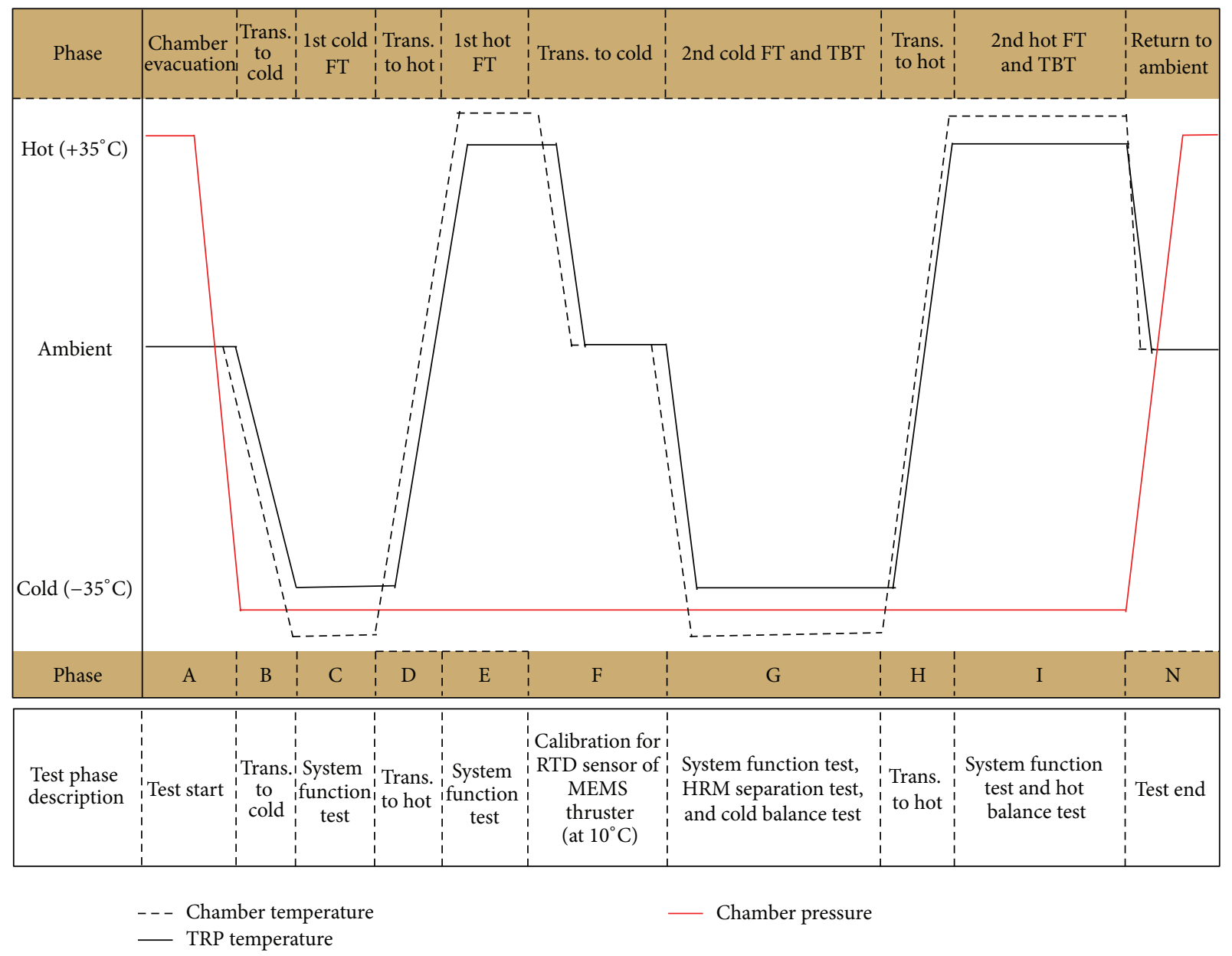

FIGURE 14: Thermal vacuum test profiles.
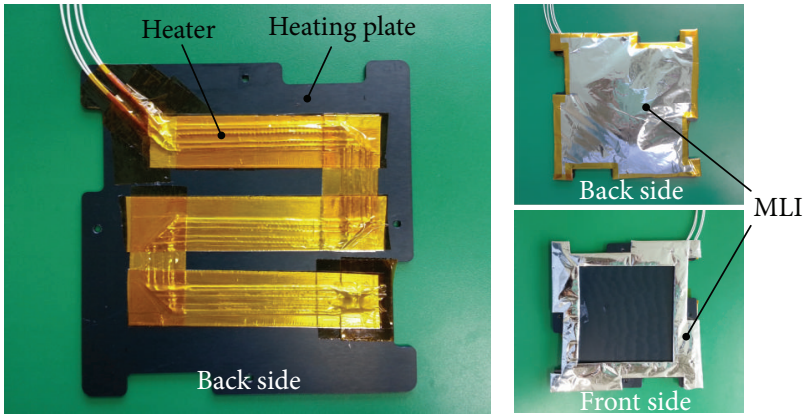

FIGURE 15: Configuration of indirect heating plate.

the configuration of front and back sides of the IDH plate made of Al-6061 with a black anodized surface treatment. The test heater was attached on the back side of the IDH to provide the required heat flux by adjusting the input power. The black anodized surface towards the $-Z$ panel side was opened and the remaining areas were covered by the test MLI for efficient radiative heat transfer to the target by minimizing heat loss from both sides of the IDH plate.

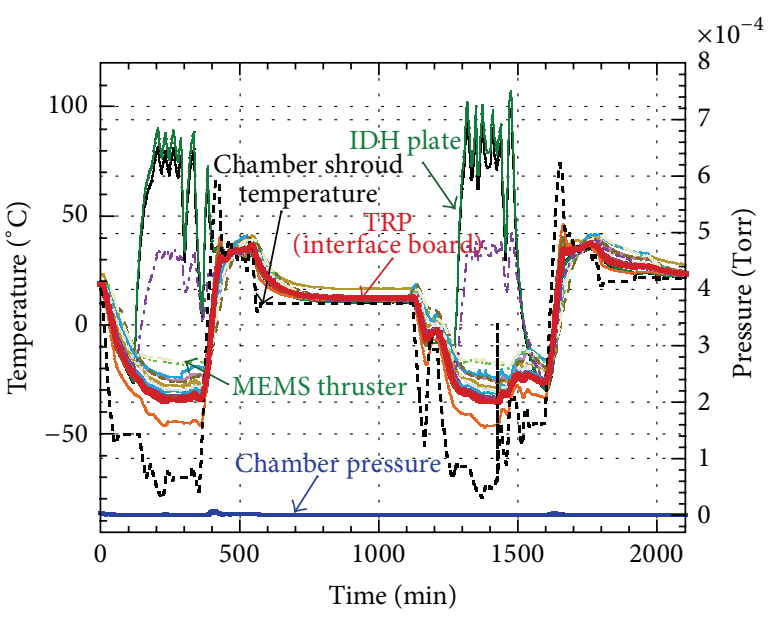

FIGURE 16: Temperature profiles of all equipment obtained from TV test.

4.2. Thermal Vacuum Test Results. Figure 16 shows the temperature profiles obtained from the TV tests. The temperature profiles for IDH operation are also plotted in the figure. The IDH functioned well, thereby allowing the temperatures of 


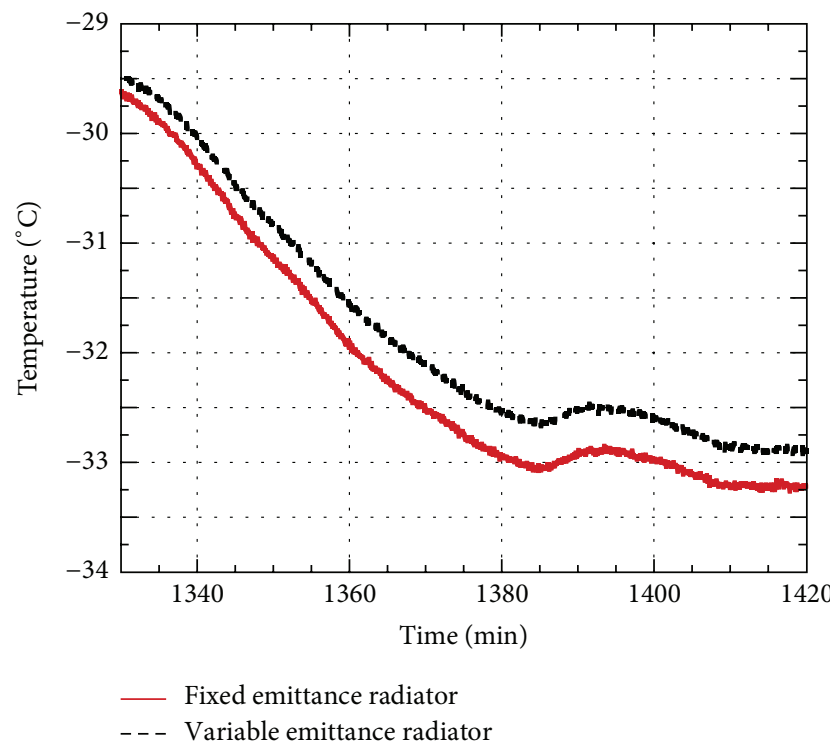

(a)

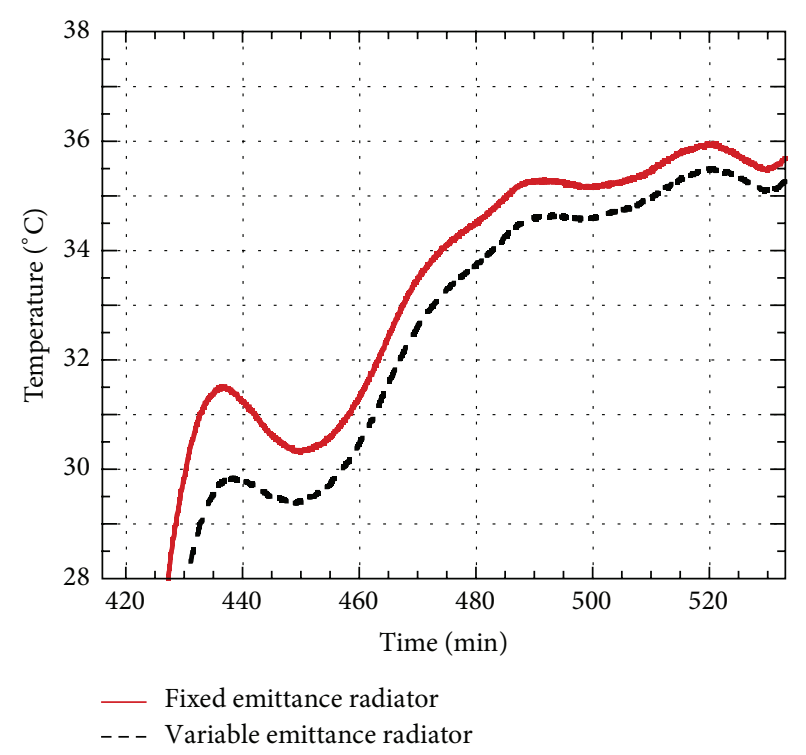

(b)

FIGURE 17: Temperature profiles of the VER and EFR ((a) transition to cold test phase, (b) transition to hot test phase).

the MEMS thruster and battery on the $-Z$ direction of the CubeSat to be locally controlled as intended by the IDH design. The test results indicated that the TV test was successfully conducted in accordance with the established test profiles shown in Figure 16, within acceptance temperature thresholds. In addition, system functional tests were successfully performed at maximum and minimum acceptance temperature plateaus without any anomalies, although the detailed test results are not described in this paper.

Figures 17(a) and 17(b) show an enlarged view of the temperature profiles obtained from the fixed and variable emittance radiators under hot and cold conditions. In all test phases, a temperature difference between the variable and fixed emittance radiators was observed. The temperature values from the VER under hot and cold conditions showed lower and higher values than the FER, respectively, because its emissivity varied according to the environment temperature. However, the difference was small compared with that of onorbit thermal analysis results shown in Figure 11 because the test temperature variation was limited to smaller range of $-35^{\circ} \mathrm{C}$ to $35^{\circ} \mathrm{C}$. Additionally, the reduction of radiating area caused by attaching thermocouples to the radiator surface having a small area of $9 \mathrm{~cm}^{2}$ also contributed to these results. Detailed characteristics of the radiator will be investigated by the STEP Cube Lab mission through on-orbit temperature data acquisition.

Figure 18 shows the temperature profile from the PCM installed on the payload plate. To verify the effectiveness of the PCM, the temperature from the payload plate is also plotted in the figure. The results clearly show the thermal characteristics of the PCM, which stores and releases latent heat according to the phase change characteristics of the material at $10^{\circ} \mathrm{C}$ as expected. In addition, no leakages of the working fluid during the test periods were observed, thereby verifying the sealing method of the PCM. The phase

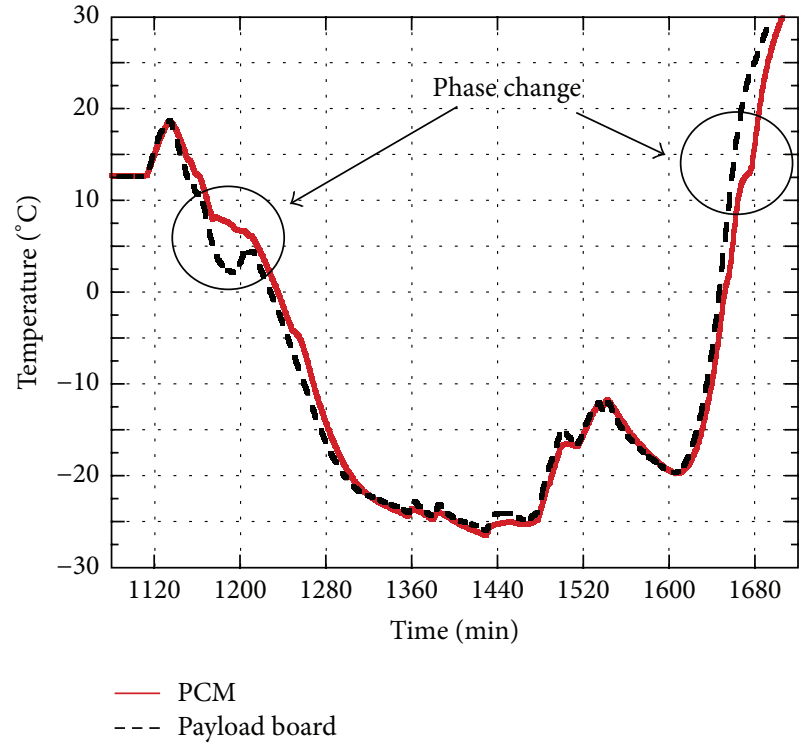

FIGURE 18: Temperature profile of the PCM.

change characteristics of the PCM will be verified through continuous temperature monitoring on-orbit.

To verify the survivability of the MEMS thruster in a thermal vacuum environment, resistance values of the microigniters were measured and compared before and after at each test phase. The variation of the resistance values for the microigniters was less than $0.7 \%$ during all test phases as shown in Figure 19. This indicates that the MEMS fabrication processes of the solid thruster array, that is, the sputtering of the Pt/Ti heater, diffusion bonding of the photosensitive glass, ultraviolet (UV) bonding, solid propellant filling under 


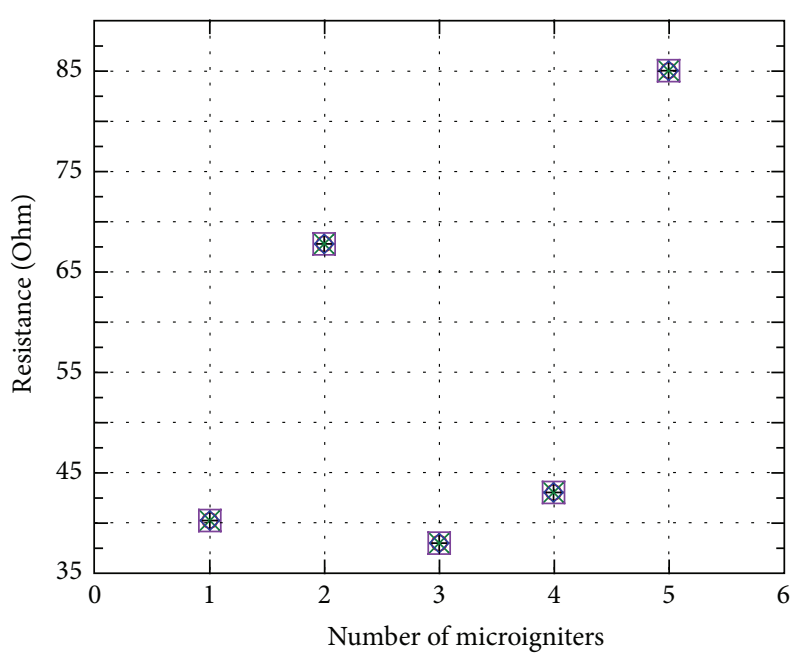

$\begin{array}{ll}\circ \text { Before TV test } & \diamond \text { 2nd cold plateau } \\ + \text { 1st cold plateau } & \square \text { 2nd hot plateau } \\ \times \text { 1st hot plateau } & \end{array}$

FIGURE 19: Resistance values for microigniters of MEMS thruster measured during each test phase.

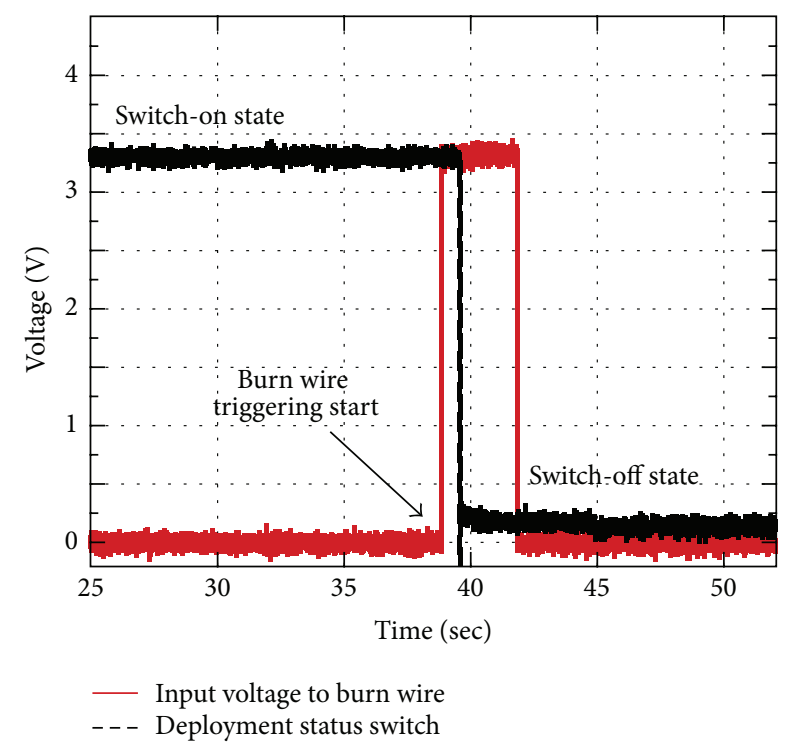

FIgURE 20: Separation test result of HRM at cold temperature condition.

vacuum, and electrode design, were verified under the specified test condition. The successful activation of nine solid thrusters at specified time intervals during on-orbit lifetime will be used as the success criterion to assess whether the aforementioned MEMS fabrication processes are applicable for use in space applications.

The separation test of the HRM was conducted in the second cold soak phase, making the worst condition for activation. Figure 20 indicates the time profiles obtained from the deployment status switch and input voltage to the fuse wire heating during the release function test of the mechanism.
TABLE 8: Summary of specific parameters variation for TMM correlation.

\begin{tabular}{lccc}
\hline Type & Items & Before & After \\
\hline $\begin{array}{l}\text { Coupling } \\
\text { condition }\end{array}$ & $\begin{array}{c}\text { Structure } / \text { interface } \\
\text { board }\left[\mathrm{W} / \mathrm{m}^{2}-{ }^{\circ} \mathrm{C}\right]\end{array}$ & 30.0 & 100.0 \\
$\begin{array}{c}\text { External panel } / \text { solar cell } \\
{\left[\mathrm{W} / \mathrm{m}^{2}{ }^{\circ} \mathrm{C}\right]}\end{array}$ & 30.0 & 200.0 \\
\hline Heat dissipation & Battery $[\mathrm{W}]$ & 0.6 & 0.08 \\
\hline
\end{tabular}

The switch-off status indicated successful release of the mechanism. In the test, an input power of $3 \mathrm{~W}$ was applied to the mechanism, which was provided by the selected Li-ion battery with a max power capability of $6 \mathrm{~W}$. The test results indicated that the mechanism guaranteed a reliable cut through the constraint wire, without failure, under the worst conditions, and the measured release time was approximately $0.71 \mathrm{~s}$.

4.3. TMM Correlation. To improve the reliability of the thermal model for prediction of on-orbit temperature of the STEP Cube Lab, TMM correlation was performed by correlating the TMM with the TB test data. The TMM correlation criteria were that less than $\pm 3^{\circ} \mathrm{C}$ temperature difference $(\Delta T)$ between the test data and analysis results and that at least $90 \%$ of the correlated items had to meet this requirement. The TMM was correlated with the hot and cold balance data. Figure 21 shows the results of $\Delta T$ before and after TMM correlation and all items were successfully correlated. In the correlation, we attempted to use the values of material and thermooptical properties summarized in Tables 5 and 6 because they are well-known factors. Minimization of $\Delta T$ was achieved by adjusting the values of the calculated conductivity and heat dissipation. The variation in specific parameters is summarized in Table 8. The most significant change was the reduction of the heat dissipation of the battery from $0.6 \mathrm{~W}$ to $0.08 \mathrm{~W}$. Initial values taken from the relevant reference [7] were preliminarily adopted for the in-orbit thermal analyses in absence of more precise information.

On-orbit temperature prediction of the STEP Cube Lab was lastly performed using the highly reliable correlated TMM, and the results of the maximum and minimum temperatures of all equipment at the worst hot and cold conditions are summarized in Table 9. The worst cold condition was divided into normal operation and emergency condition with minimum heat dissipation of OBC, EPS, and communication boards. The results show that all the components are within their allowable operating temperature ranges, as specified in Table 3, indicating that the thermal design based on the passive approach was sufficient to ensure stable operation of the STEP Cube Lab. However, in the worst cold emergency case, when the satellite is in eclipse, the battery temperature dropped to $-8.1^{\circ} \mathrm{C}$. This could damage the battery, although the predicted temperature was within the range of the allowable temperature summarized in Table 3. This could be easily solved by implementing an on/off type of heater control with set-points to maintain the battery above the recommended minimum operative temperature of $0^{\circ} \mathrm{C}$. 


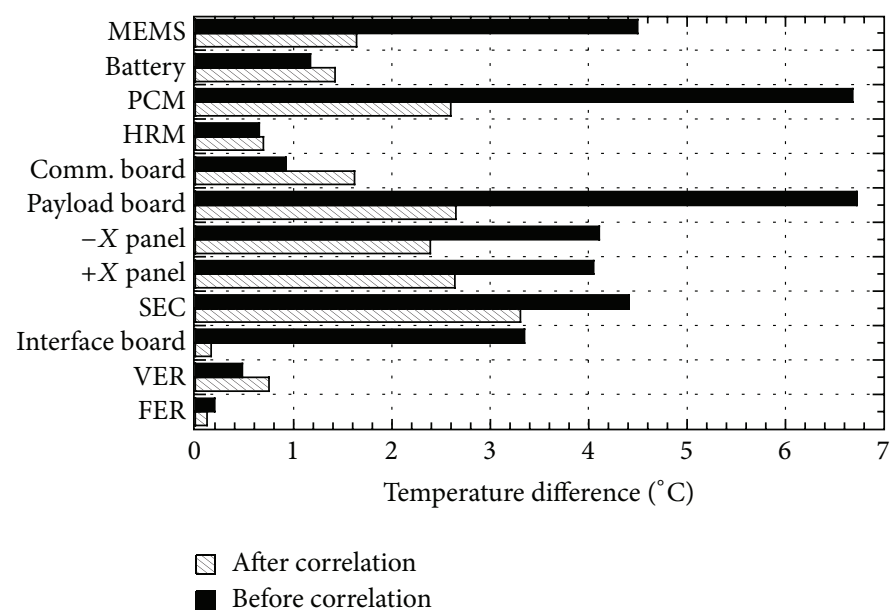

(a)

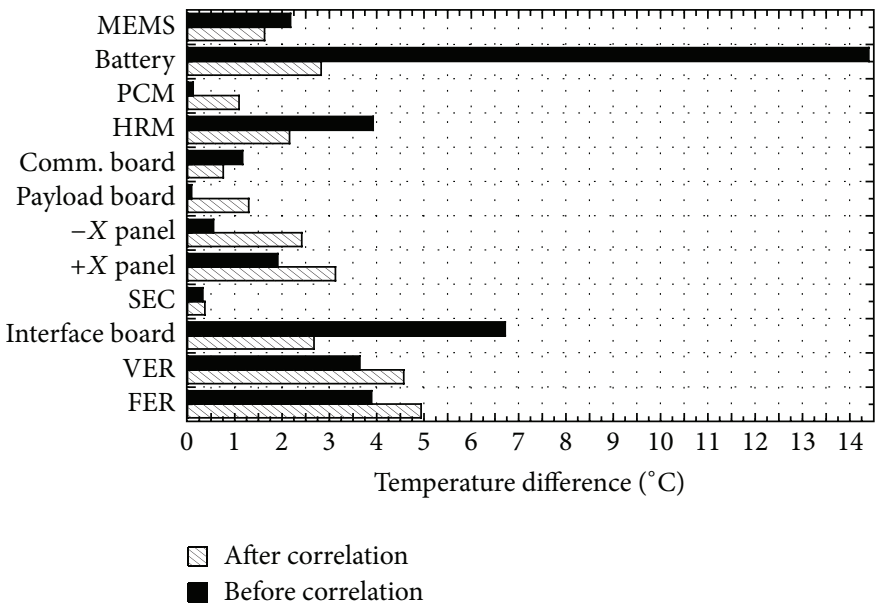

(b)

Figure 21: Before and after TMM correlation results of $\Delta T$ between test results and prediction by analysis ((a) cold balance correlation, (b) hot balance correlation).

TABLE 9: On-orbit temperature prediction using the correlated TMM with TB test.

\begin{tabular}{|c|c|c|c|c|c|c|}
\hline \multirow{3}{*}{ Component } & \multicolumn{3}{|c|}{ Before correlation $\left({ }^{\circ} \mathrm{C}\right)$} & \multicolumn{3}{|c|}{ After correlation $\left({ }^{\circ} \mathrm{C}\right)$} \\
\hline & Hot operation & Cold operation & Cold emergency & Hot operation & Cold operation & Cold emergency \\
\hline & $T_{\max }$ & $T_{\min }$ & $T_{\min }$ & $T_{\max }$ & $T_{\min }$ & $T_{\min }$ \\
\hline$+X$ panel & 56.67 & -39.21 & -40.57 & 56.20 & -43.90 & -44.75 \\
\hline$-X$ panel & 50.75 & -25.06 & -25.84 & 49.89 & -33.64 & -34.52 \\
\hline$+Y$ panel & 22.95 & -37.40 & -38.40 & 33.54 & -42.08 & -44.75 \\
\hline$-Y$ panel & 30.88 & -31.11 & -32.16 & -3.78 & -39.13 & -43.36 \\
\hline I/F board & 13.60 & -30.50 & -31.54 & 36.16 & -25.60 & -25.77 \\
\hline GPS board & 18.62 & -2.07 & -4.35 & 15.67 & -8.19 & -8.80 \\
\hline OBC board & 17.24 & -8.54 & -10.28 & 26.62 & -15.68 & -18.21 \\
\hline Comm. board & 20.94 & -4.02 & -6.13 & 19.46 & -9.47 & -11.98 \\
\hline Power board & 20.61 & -11.22 & -12.55 & 14.61 & -20.49 & -22.76 \\
\hline Battery & 35.78 & -1.38 & -3.49 & 26.90 & -3.78 & -8.07 \\
\hline MEMS & 25.67 & -3.71 & -4.79 & 30.96 & -26.77 & -30.41 \\
\hline SEC & 67.63 & -29.68 & -30.50 & 58.20 & -35.20 & -36.18 \\
\hline PCM & 19.71 & -3.16 & -5.23 & 19.52 & -7.18 & -9.39 \\
\hline HRM & 15.66 & 3.10 & 1.27 & 17.25 & 2.03 & -0.20 \\
\hline
\end{tabular}


TABLE 10: On-orbit temperature prediction after thermal design modification on the battery.

\begin{tabular}{|c|c|c|c|c|c|c|}
\hline \multirow[b]{2}{*}{ Component } & \multicolumn{3}{|c|}{ Without MLI on the battery $\left({ }^{\circ} \mathrm{C}\right)$} & \multicolumn{3}{|c|}{ With MLI on the battery $\left({ }^{\circ} \mathrm{C}\right)$} \\
\hline & $\begin{array}{l}\text { Hot operation } \\
T_{\max } \\
\end{array}$ & $\begin{array}{c}\text { Cold operation } \\
T_{\min } \\
\end{array}$ & $\begin{array}{c}\text { Cold emergency } \\
T_{\min } \\
\end{array}$ & $\begin{array}{c}\text { Hot operation } \\
T_{\max } \\
\end{array}$ & $\begin{array}{c}\text { Cold operation } \\
T_{\min } \\
\end{array}$ & $\begin{array}{c}\text { Cold emergency } \\
T_{\min } \\
\end{array}$ \\
\hline$+X$ panel & 56.20 & -43.90 & -44.75 & 56.88 & -44.12 & -44.29 \\
\hline$-X$ panel & 49.89 & -33.64 & -34.52 & 52.15 & -34.39 & -34.41 \\
\hline$+Y$ panel & 33.54 & -42.08 & -44.75 & 33.52 & -41.90 & -43.06 \\
\hline$-Y$ panel & -3.78 & -39.13 & -43.36 & -2.37 & -40.32 & -40.58 \\
\hline $\mathrm{I} / \mathrm{F}$ board & 36.16 & -25.60 & -25.77 & 37.96 & -25.51 & -25.75 \\
\hline GPS board & 15.67 & -8.19 & -8.80 & 18.24 & -7.21 & -9.91 \\
\hline OBC board & 26.62 & -15.68 & -18.21 & 27.30 & -15.53 & -16.10 \\
\hline Comm. board & 19.46 & -9.47 & -11.98 & 20.35 & -9.55 & -10.83 \\
\hline Power board & 14.61 & -20.49 & -22.76 & 18.32 & -20.47 & -21.20 \\
\hline Battery & 26.90 & -3.78 & -8.07 & 27.81 & 2.64 & 1.84 \\
\hline MEMS & 30.96 & -26.77 & -30.41 & 29.46 & -28.27 & -28.57 \\
\hline SEC & 58.20 & -35.20 & -36.18 & 59.45 & -36.18 & -36.04 \\
\hline PCM & 19.52 & -7.18 & -9.39 & 20.36 & -7.44 & -8.64 \\
\hline HRM & 17.25 & 2.03 & -0.20 & 17.26 & 1.82 & 0.60 \\
\hline
\end{tabular}

However, in this study, we propose the application of MLI to the battery in order to minimize the design modifications to the existing CubeSat flight model already verified through environment tests. The thermal analysis results summarized in Table 10 showed that the minimum temperature of the battery increased to $1.84^{\circ} \mathrm{C}$ by applying the MLI at the worst cold emergency condition. The calculated maximum temperature at the worst hot operation condition was $27.81^{\circ} \mathrm{C}$, with a margin of $32^{\circ} \mathrm{C}$, with respect to the requirement of $+60^{\circ} \mathrm{C}$. Accessing to the battery is very easy as it is located in close proximity to the MEMS thruster, as shown in Figure 8(b). Therefore, the additional MLI installation on the battery can be easily accomplished by demating the MEMS thruster module on flexure-like brackets as shown in Figure 1(b), without demating the remaining parts of the CubeSat.

\section{Conclusion}

This paper describes thermal design and validation of a $1 \mathrm{U}$ standardized pico-class satellite of STEP Cube Lab developed for the purpose of on-orbit verification of technical results from space-related research conducted in domestic universities. In this paper, firstly, a system overview of the STEP Cube Lab, including the description of five payloads, was introduced. Next, the thermal design to guarantee successful mission objective by satisfying the temperature requirement of on-board equipment was described, and the effectiveness of the thermal design and the main functions of the STEP Cube Lab were verified under space simulated thermal vacuum environment. One of the features of thermal vacuum test performed in this study was to use an indirect heating plate to simulate on-orbit temperature condition of the satellite. In addition, a correlated thermal mathematical model of the STEP Cube Lab with higher reliability was created by using experimental data obtained from thermal balance test. Onorbit thermal analysis results based on the correlated thermal mathematical model shows that the thermal design based on the passive approach ensures stable operation of the system within allowable operating temperature ranges.

\section{Competing Interests}

The authors declare that they have no competing interests.

\section{Acknowledgments}

This research was supported by a research fund (2015) by Chosun University.

\section{References}

[1] H. Heidt, J. Puig-Suari, A. S. Moore, S. Nakasuka, and R. J. Twiggs, "CubeSat: a new generation of picosatellite for education and industry low-cost space experimentation," in Proceeding the 14th Annual AIAA/USU Conference on Small Satellites, vol. 32, Logan, Utah, USA, August 2000.

[2] M. Komatsu and S. Nakasuka, "University of Tokyo nano satellite project PRISM," Transactions of the Japan Society for Aeronautical and Space Sciences, vol. 7, no. 26, pp. 19-24, 2009.

[3] M. W. Smith, S. Seager, C. M. Pong et al., "ExoplanetSat: detecting transiting exoplanets using a low-cost CubeSat platform," in Space Telescopes and Instrumentation: Optical, Infrared, and Millimeter Wave, vol. 7731 of Proceedings of the SPIE, pp. 66-78, San Diego, Calif, USA, July 2010.

[4] C. J. Fong, A. Lin, A. Shie et al., "Lessons learned of NSPO's Picosatellite Mission: YamSat-1A, 1B \& 1C," in Proceedings of the 16th Annual AIAA/USU Conference on Small Satellite, no. 60, The American Institute of Aeronautics and Astronautics, 2002.

[5] V. Baturkin, "Micro-satellites thermal control-concepts and components," Acta Astronautica, vol. 56, no. 1-2, pp. 161-170, 2005.

[6] J. Yoo, H. Jin, J. Seon et al., "Thermal analysis of TRIO-CINEMA mission," Journal of Astronomy and Space Science, vol. 29, no. 1, pp. 23-31, 2012. 
[7] W. Ley, E. Plescher, A. Scholz, and J. Piepenbrock, "COMPASS-1 picosatellite project," in Proceedings of the 16th IAA Symposium on Small Satellites for Earth Observation, 2007.

[8] A. Scholz, W. Ley, B. Dachwald, J. J. Miau, and J. C. Juang, "Flight results of the COMPASS-1 picosatellite mission," Acta Astronautica, vol. 67, no. 9-10, pp. 1289-1298, 2010.

[9] S. Corpino, M. Caldera, F. Nichele, M. Masoero, and N. Viola, "Thermal design and analysis of a nanosatellite in low earth orbit," Acta Astronautica, vol. 115, pp. 247-261, 2015.

[10] E. Escobar, M. Diaz, and J. Zagal, "Design automation for satellite passive thermal control," in Proceedings of the $4 \mathrm{~S}$ Symposium, Portoroz, Slovenia, June 2012.

[11] Y. Shimakawa, T. Yoshitake, Y. Kubo et al., "A variable-emittance radiator based on a metal-insulator transition of $(\mathrm{La}, \mathrm{Sr}) \mathrm{MnO}^{3}$ thin films," Applied Physics Letters, vol. 80, no. 25, pp. 48644866, 2002.

[12] A. Kumar, A. Sekar, D. N. Siddhartha, and K. V. Govinda, "Phase change materials (PCM) for thermal control during spacecraft transportation," International Journal of Mechanical and Industrial Engineering, vol. 3, no. 1, pp. 28-32, 2013.

[13] D. G. Gilmore, Spacecraft Thermal Control Handbook, Volume 1: Fundamental Technologies, The Aerospace Corporation, 2nd edition, 2002.

[14] H.-U. Oh and T. Y. Park, "Experimental feasibility study of concentrating photovoltaic power system for cubesat applications," IEEE Transactions on Aerospace and Electronic Systems, vol. 51, no. 3, pp. 1942-1949, 2015.

[15] J. K. Lee, K. H. Kim, and S. J. Kwon, "Design, fabrication and testing of MEMS solid propellant thruster array chip on glass wafer," Journal of Sensors and Actuators A: Physical, vol. 157, no. 1, pp. 126-134, 2010.

[16] M. J. Lee, Y. K. Lee, and H. U. Oh, "Performance evaluation of hinge driving separation nut-type holding and releasing mechanism triggered by nichrome burn wire," International Journal of Aeronautical and Space Sciences, vol. 16, no. 4, pp. 602-613, 2015.

[17] A. R. Samir, Passive attitude stabilization for small satellites [M.S. thesis], University of Kentucky, Lexington, Ky, USA, 2010.

[18] http://www.gomspace.com/.

[19] T. D. Panczak, S. G. Ring, M. J. Welch, D. Johnson, B. A. Cullimore, and D. P. Bell, Thermal Desktop User's Manual, C \& R Technologies, 2008.

[20] F. M. Michael, Radiative Heat Transfer, The Academic Press, 2nd edition, 2003.

[21] K. Shimazaki, A. Ohnishi, and Y. Nagasaka, "Development of spectral selective multilayer film for a variable emittance device and its radiation properties measurements," International Journal of Thermophysics, vol. 24, no. 3, pp. 757-769, 2003. 


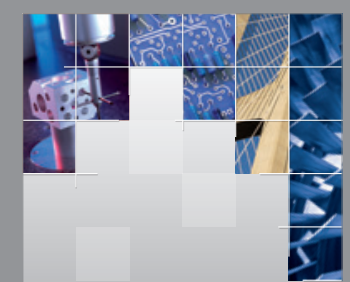

\section{Enfincering}
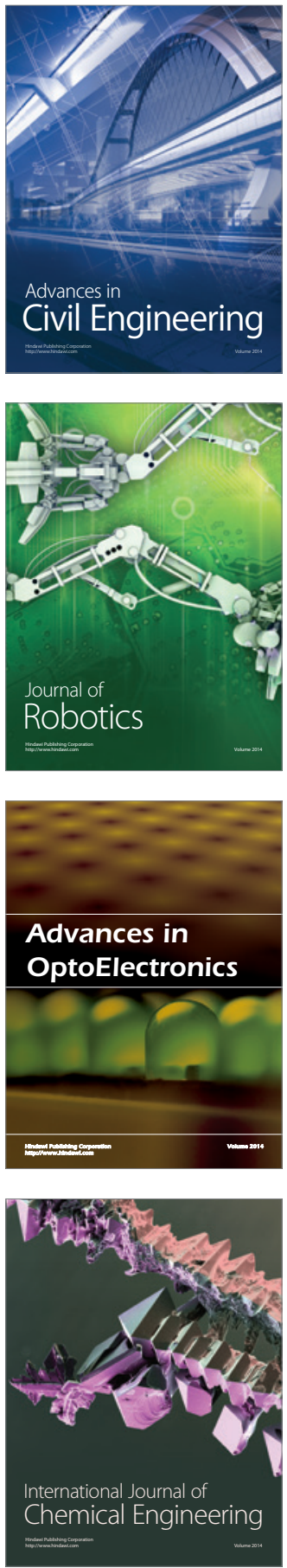

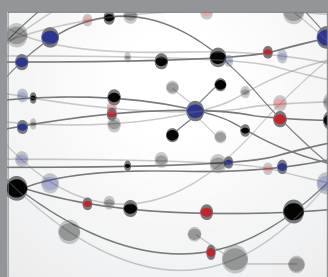

The Scientific World Journal

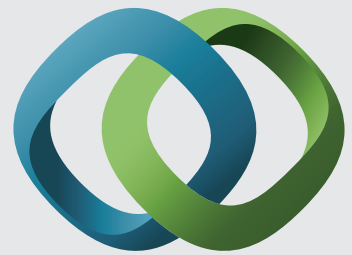

\section{Hindawi}

Submit your manuscripts at

http://www.hindawi.com
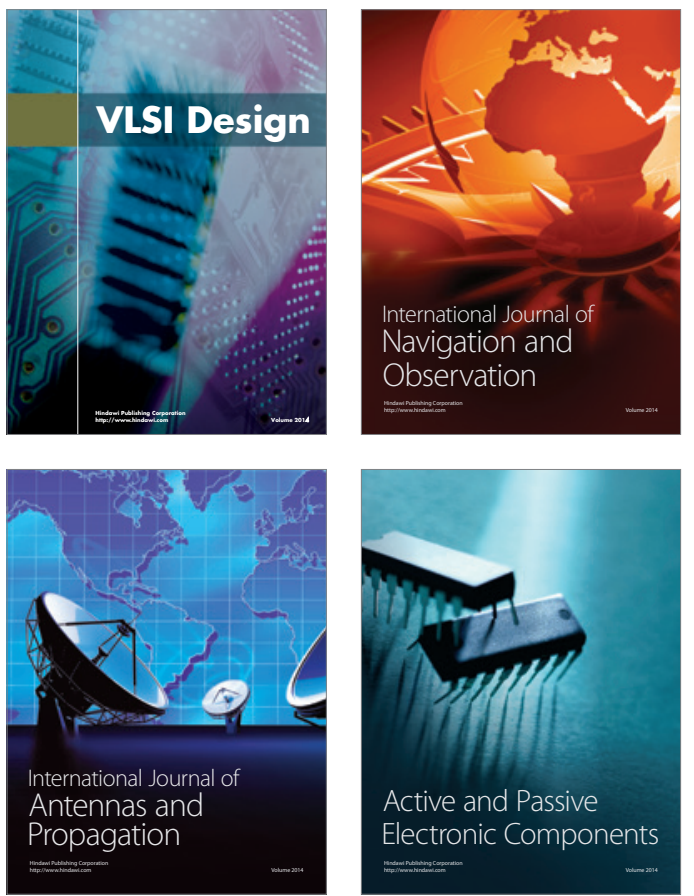
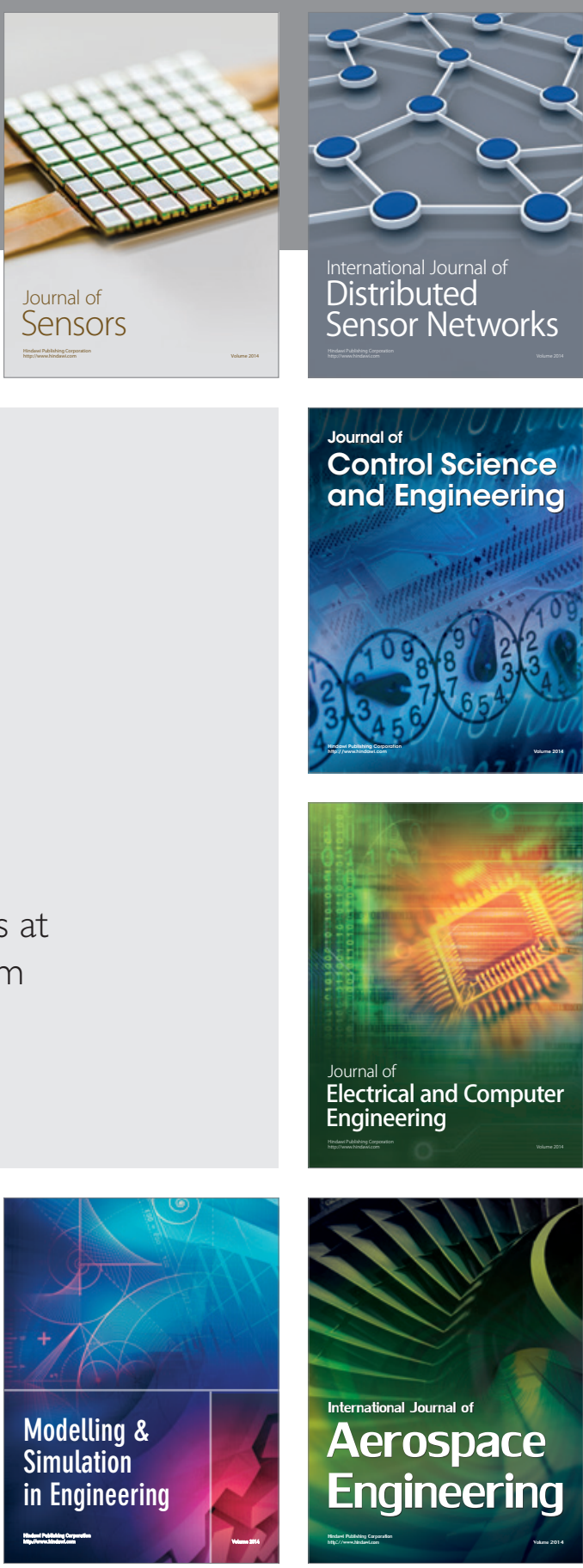

International Journal of

Distributed

Sensor Networks

Journal of

Control Science

and Engineering
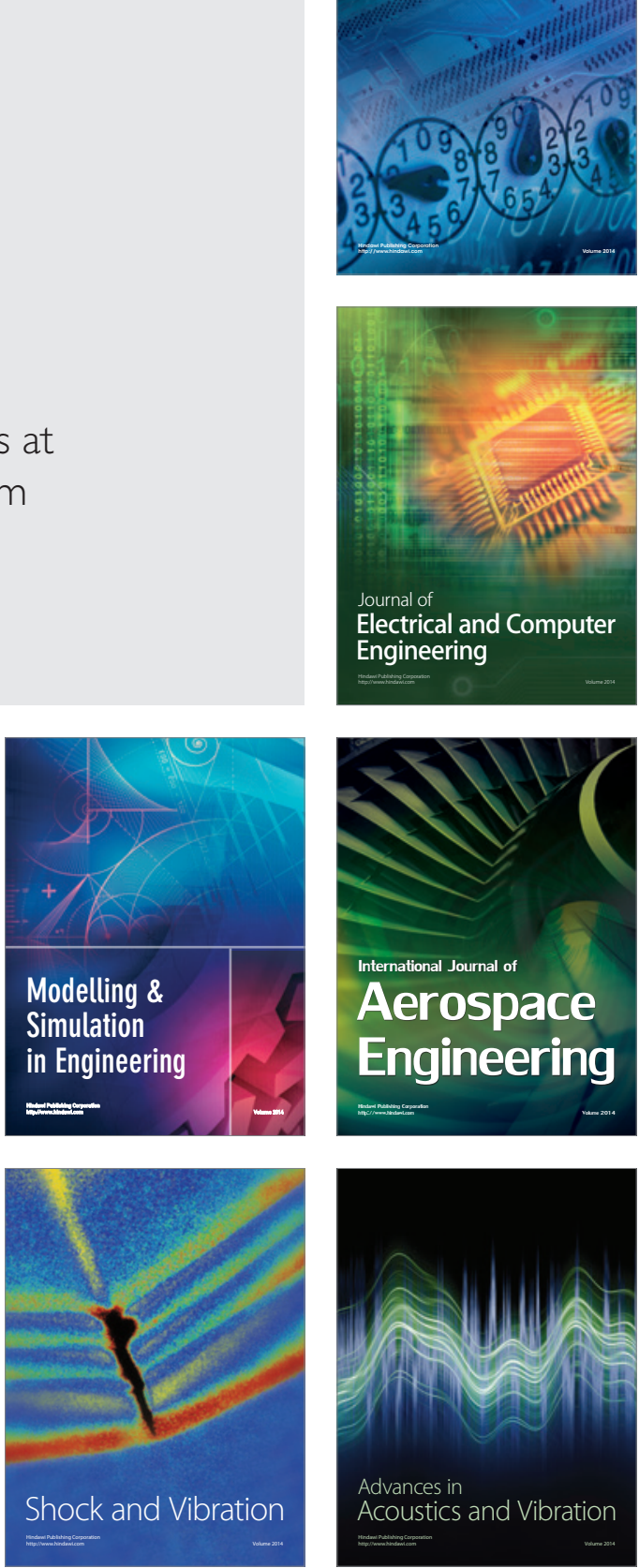